\title{
Adjuvants and delivery systems in veterinary vaccinology: current state and future developments
}

Heegaard, Peter M. H.; Dedieu, Laurence; Johnson, Nicholas; Potier, Marie-Frédérique Le; Mockey, Michael; Mutinelli, Franco; Vahlenkamp, Thomas; Vascellari, Marta; Sørensen, Nanna Skall

Published in:

Archives of Virology

Link to article, DOI:

10.1007/s00705-010-0863-1

Publication date:

2011

Link back to DTU Orbit

Citation (APA):

Heegaard, P. M. H., Dedieu, L., Johnson, N., Potier, M-F. L., Mockey, M., Mutinelli, F., Vahlenkamp, T., Vascellari, M., \& Sørensen, N. S. (2011). Adjuvants and delivery systems in veterinary vaccinology: current state and future developments. Archives of Virology, 156(2), 183-202. https://doi.org/10.1007/s00705-010-0863-1

\section{General rights}

Copyright and moral rights for the publications made accessible in the public portal are retained by the authors and/or other copyright owners and it is a condition of accessing publications that users recognise and abide by the legal requirements associated with these rights.

- Users may download and print one copy of any publication from the public portal for the purpose of private study or research.

- You may not further distribute the material or use it for any profit-making activity or commercial gain

- You may freely distribute the URL identifying the publication in the public portal 


\section{Adjuvants and delivery systems in veterinary vaccinology: Current state and future developments}

Peter M. H. Heegaard ${ }^{1}$, Laurence Dedieu ${ }^{2}$, Nicholas Johnson ${ }^{3}$, Marie-Frédérique Le Potier ${ }^{4}$ Michael Mockey ${ }^{2}$, Franco Mutinelli ${ }^{5}$, Thomas Vahlenkamp ${ }^{6}$ Marta Vascellari ${ }^{5}$, Nanna Skall Sørensen ${ }^{1}$

\footnotetext{
${ }^{1}$ National Veterinary Institute, Technical University of Denmark, Department of Veterinary Diagnostics and Research, 27, Bülowsvej, 1790 Copenhagen V, Denmark ${ }^{2}$ CIRAD, UMR CMAEE Contrôle des Maladies Animales, F-34398 Montpellier, France ${ }^{3}$ Veterinary Laboratories Agency, New Haw, Addlestone, Surrey, KT15 3NB, United Kingdom

${ }^{4}$ Anses Laboratoire de Ploufragan, Unité virologie et immunologie porcines, Les Croix, 22440 Ploufragan, France

${ }^{5}$ Istituto Zooprofilattico Sperimentale delle Venezie, Histopathology Department, Viale dell'Universita' 10 - 35020 Legnaro (PD), Italy

${ }^{6}$ Friedrich-Loeffler-Institute, Federal Research Institute for Animal Health, Südufer 10, 17493 Greifswald-Insel Riems, Germany
} 


\section{Abstract}

Modern adjuvants should induce strong and balanced immune responses and it is often desirable to induce specific types of immune responses. As an example efficient Thl-immunity inducing adjuvants are highly in demand. Such adjuvants promote good cellular mediated immunity against subunit vaccines having low immunogenicity themselves. The development of such adjuvants may take advantage of the increased knowledge of the molecular mechanisms and factors controlling these responses. However, the knowledge of such molecular details of immune mechanisms are relatively scarce in other species than human and laboratory rodents and, in addition, there are special considerations pertaining to the use of adjuvants in veterinary animals, such as production and companion animals. With a focus on veterinary animals, the review highlights a number of approaches being pursued, including cytokines, CpG oligonucleotides, microparticles and liposomes. 


\section{Introduction}

Vaccines are compositions containing non-pathogenic, and sometimes noninfectious, variants of infectious or transmissible pathogenic agents. When administered to a host they induce short-term (within weeks) as well as longlasting (years, sometimes lifelong) specific immunity in the vaccinated host against the particular pathogen imitated by the vaccine. Immunity can be defined as preparedness and capacity to neutralize a given agent by appropriate, protective defence responses.

Since the late 18th century discovery by Jenner that vaccinia (cowpox virus) could be used a reliable vaccine against the related smallpox virus (108) vaccine development has been largely empirical, using live attenuated or killed microorganisms and/or detoxified versions of their toxins (38, 71, 119, 121). Still, mass vaccination programmes have eradicated smallpox and dramatically reduced polio in humans and eradicated rinderpest in cattle (74, 116) and vaccination remains the most cost-effective way of controlling infectious diseases (71). Closely linked to vaccine development, vaccine potentiating compounds (adjuvants) have continuously been developed. They comprise a plethora of working mechanisms and a broad variety of molecules some of which have been used widely for many years $(34,128,135)$.

Although vaccines for use in livestock animals like cattle, pigs, sheep, goat, poultry and farmed fish as well as in companion animals like dogs, cats, and horses have the same general goal as those used for humans, there are a range of different demands to be met. Some of these are related to the use of the animal for human consumption or as companion animals, while others relate to how to design and use vaccines in the best way, considering animal production (rearing) practices, herd epidemiology and animal trade. With livestock animals there is also a considerable focus on direct (vaccine) and indirect (effect on growth rates) costs of vaccines which is not a primary concern for companion animals. Additional points are the challenges and opportunities offered by different species (e.g. fish and chickens) with respect to administration practices and routes, especially in order to vaccinate high numbers of animals in a short time.

Thus the use of adjuvants and, especially, the rational development of new adjuvants and immunostimulators for veterinary animals demand special attention and it is appropriate to consider some recent examples of adjuvant research with a specific focus on their use in animals of veterinary significance.

\section{Background}

A number of recent reviews giving excellent updates on the immune system and the mechanisms of adjuvants have been published recently $(1,48,125)$. For the sake of clarity and consistency a few central concepts will be restated here.

The pivotal discrimination between threats (pathogens and their toxins) and nonthreats (self antigens, innocuous environmental antigens) is exerted by the physiological barriers of the body together with the innate part of the immune system $(29,120)$. The central innate cellular actors, the dendritic cells (DC) when activated secrete potent pleiotropic signal molecules activating the adaptive immune system to respond against any extraneous molecule involved. If the innate immune system is not activated adaptive immune responses are very rarely induced. A limited number of highly conserved molecular structures specific to microbial pathogens, the so-called pathogen-associated molecular patterns (PAMPs) are well-described innate immune triggers (57). When bound by pattern recognition receptors (PRRS) including the Toll-like receptors (TLR) on DCs very fast innate responses are induced (120). The TLR family was named after the toll protein originally found to be involved in Drosophila development and later found to have structural homologies with the human IL-1 receptor 
implying immunological functions. This led to the identification of a growing family of vertebrate TLR, each associated with a particular ligand (agonist) type and cellular location (Table 1).

While the distinction between threats and non-threats takes place in the innate immune system self - non-self discrimination takes place in the adaptive immune system after activation by the innate immune system. The adaptive immune system with its wide range of exquisitely fine-tuned antigen-specific responses, controlled by $\mathrm{T}-$ and $\mathrm{B}-\mathrm{cells}$ in combination with antigen presenting cells (APCs) brings antigenic specificity to immune responses and provides memory (longlasting immunity). Memory is a central asset of immunity $(20,71)$ and relies upon the generation of long-lived optimally reactive antigen-specific $T$ and $B$ cells and long-lived plasma cells producing high-affinity antibodies (20,71). A subset of effector T cells, after performing their tasks at the site of infection survives and differentiates into such long-lasting memory $\mathrm{T}$ cells responding rapidly to low doses of antigen (86, 125). Memory B cells rapidly express high affinity antibodies (125) upon antigenic restimulation. While the composition of the preferred immune response induced by a vaccine depends on the type of infectious agent targeted by the vaccine, a vaccine should always induce immunological memory.

The innate immune system also controls the type of adaptive response. This is mediated by soluble molecules secreted by activated DC $(120,125,140$ ) (see Figure 1, Suppl. info.). Some pathogens will activate DCs to produce cytokines (including interleukin (IL) -12) stimulating development of $\mathrm{T}$ helper cells that produce interferon- (IFN-) Y and promote cell-mediated immunity (Th1 cells). Other types of stimuli (160) induce Th2 cells producing IL-4, IL-5 and IL-13 promoting antibody-based immunity efficient at neutralizing extracellular pathogens and toxins (86, 125) (see Figure 1, Suppl. info.). Also, generation of immunological memory is intimately dependent on innate immune reactions accompanying the initial encounter between host and vaccine (125).

Adjuvants primarily affect the innate, immunity-shaping pre-primary immune response and innate immunity has been called "The Science of Adjuvants" (125). Adjuvants must enhance both specific immune responses as well as increase immunological memory and improve protection through stimulation of optimal types of immunity. Adjuvants are also required to have low levels of adverse effects, including for veterinary animals adverse effects that negatively influences the growth of the animal, the reproduction rate, the comfort and welfare of the animal or cause carcass blemish. Adjuvants must also be stable and easy to use providing convenient injectability.

Traditional adjuvants are mostly complex and not very well-defined mixtures of surface-active compounds, microbial components and/or various polymers and lipids and can be classified into delivery systems/antigen modifiers or immune potentiators, or combinations of these (see Table 2) (42, 94). Delivery systems/antigen modifiers function by presenting, aggregating and/or polymerising antigens $(42,48,161)$. Immunopotentiators include PAMP structures, endogenous immunoactive compounds, (cytokines a.o.) and a range of surface active molecules directly stimulating innate immune cells. Examples of PAMP structures used as immunopotentiators are monophosphoryl lipid A and unmethylated CPG oligonucleotides $(42,48)$. Next to alum (aluminium salts), which is still the only adjuvant class generally approved for human use, emulsions of water-in-oil or vice versa stabilised by surfactants, are the most widely used adjuvant systems and include Freund's adjuvant. Other well-known delivery systems include liposomes and microparticles, which are inert carriers of antigen unless immune potentiators have been added to them (48, 119). 
Modern vaccines based on sub-units of pathogens, e.g. purified proteins are often unable to evoke strong immune responses. Therefore adjuvants, in particular safe and efficient Th1 inducing adjuvants are in increasing demand (134). Freund's complete adjuvant $(1,48)$ is an efficient Th1 inducer however has a high and generally unacceptable level of adverse local effects.

\section{Adjuvant safety: Efficiently inducing immunity without causing harm.}

\section{Adverse effects and potential hazards}

Mild local and systemic reactions to vaccines and their adjuvants are to be expected as a natural consequence of vigorously stimulating the immune system $(129,137)$. These adverse effects are influenced by the interactions of the specific adjuvant and antigen and the type of adverse reaction will vary according to the vaccine used. For example, temperature rise with associated reduction or cessation of feeding, dullness and reduced milk production (if lactating) is frequently associated with live vaccines. Bacterial crude extracts often induce strong local reactions when administered in emulsion, as they may contain strongly immunostimulating compounds like lipopolysaccharide or peptidoglycan fragments, responsible for the induction of secondary reactions.

Many vaccine side effects are trivial and of short duration and are usually associated with live vaccines. Sometimes adjuvants in a vaccine can cause an adverse reaction, sometimes latent infections can be reactivated, and sometimes an animal may fail to respond (107). Other well-known side effects include: transient swelling at the site of injection and a reaction that may change coat colour in the area; transient fever; respiratory distress, salivation, vomiting, diarrhoea, urticaria; arthritis, uveitis, anorexia, soreness, lethargy; reduced fertility, foetal deformities and abortion. Considering the many millions of doses of vaccine sold annually and used in farm animals, such adverse side effects are very rare (131) when vaccines are used as intended by the manufacturers, and safety testing of vaccines helps prevent their occurrence. With killed vaccines the most common side effects are local, presenting themselves around the injection site, especially if using an adjuvant that delays antigen release. However, such reactions can also occur in vaccines not containing an adjuvant and therefore it is usually advised that the vaccine, particularly if injected subcutaneously, should be introduced into an area of the animal not used for human consumption such as behind the animal's ear or in the area of the chest wall behind the elbow. Then if there is any residual vaccine left or any reaction to it, there will be neither involvement of an edible part of the carcass nor trim losses in food animals (131).

\section{Injection site reactions}

Injection site reactions are of great concern in food-producing animals as reviewed by Roth (129) and Spickler and Roth (137) in cattle, swine, sheep and chicken. They may lead to unacceptable blemishes in, or decreased quality of, meat intended for human consumption. There are many possible causes of injection site lesions, including organisms introduced with a contaminated needle, live contaminating organisms in the vaccine, adjuvant induced reactions, cytokine release, hypersensitivity reactions (type I, II, III, or IV), trauma, and haemorrhage. Injections of vaccines into the subcutis can result in the development of palpable granulomatous nodules due to adjuvants and other highly immunostimulatiory vaccine components inciting persistent local immunologic responses (50). Histologic changes consist of a localized area of deep dermal or subcutaneous necrosis containing foreign material thought to be adjuvant or vaccine components. The central zone of foreign and necrotic material is bordered by macrophages and multinucleated giant cells with a peripheral zone of lymphocytes and variable numbers of plasma cells and eosinophils (foreign body granuloma) (Figure 2, suppl. info.). Macrophages usually contain amphiphilic 
granular foreign material. Lymphoid follicular development at the margins of these lesions can be extensive. Vaccine-associated granulomatous inflammation has also been reported in the peritoneum (123) and muscle (79) of fishes, with consequent retarded growth and downgrading during processing.

\section{Vaccine-induced neoplastic disease}

Although injection site lesions often heal without serious consequences, in cats there is a causal relationship between postvaccination inflammation and development of fibrosarcomas, osteosarcomas, rhabdomyosarcomas, malignant fibrous histiocytomas, and chondrosarcomas (53). Antigen load and degree of persistent inflammation and eventual fibroblastic proliferation caused by subcutaneous vaccine administration are thought to be important factors predisposing to tumour development in cats. It is speculated that during tissue repair, fibroblasts or myofibroblasts are stimulated by the immunogenic substances in the vaccine reaction site and this, in combination with other factors such as oncogene alterations or unidentified carcinogens, leads to malignant transformation of cells. Tumour development can take months to years, with eventual neoplastic transformation of mesenchymal cells.

The incidence of such fibrosarcomas occurring at sites commonly used for vaccination in cats has increased in recent years (53), and although still regarded as rare (estimates of approx 1 to 2 cases/10,000 vaccinated cats), vaccine-associated fibrosarcomas are arguably the most serious vaccine adverse events reported in cats (Figure 3. Suppl. info.). More recently a similar pathological entity has been reported also in ferrets (109) and dogs (153). Histologically, feline postinjection fibrosarcomas are characterized by inflammatory peritumoural infiltration, multinucleated giant cells, and myofibroblastic cells.

Vaccine-associated sarcomas were recognized in 1991 following the introduction of an aluminium adjuvanted FeLV vaccine and the transition from modified-live rabies virus vaccines to adjuvanted killed rabies virus vaccines in the mid 1980s. Epidemiological evidence of a causal association between vaccination with aluminium salt adjuvanted rabies virus and FeLV vaccines has also been established (70) and vaccine adjuvant-induced inflammation at the injection site has been implicated as the cause (61). However, results of a multicenter casecontrol study (70) of risk factors did not support the hypothesis that the risk of sarcoma formation was associated with specific brands or types of vaccines. A direct association between the presence or severity of postvaccinal inflammation and tumour risk has not specifically been established, but after taking all currently available evidence into consideration, the 2006 American Association of Feline Practitioners Feline Vaccine Advisory Panel Report suggested that veterinarians use less inflammatory products whenever possible (127). Adjuvanted rabies vaccines appear to induce greater inflammation than do nonadjuvanted rabies vaccines, and the same appears true for FeLV vaccines. Administering injectable vaccines in specific recommended sites on the body facilitates monitoring vaccine site reactions and managing sarcomas, should they develop (127) .

\section{Safety of oil-based adjuvants}

Oil-based adjuvants are among the most efficient adjuvants known and they are in wide use for veterinary vaccines, however they may induce local and general reactions, like granuloma, abscesses or fever (8). The mineral oils in use for these purposes are a mix of several hydrocarbon chains of different lengths. Small chains are efficient but induce local reactions, whereas longer chains (> C14) are safer but less efficient. Medium-length chains are preferred (C16-C20). The solubilising and detergent properties of small chains are probably responsible for these local reactions. Highly purified non mineral oils are well tolerated as they are rapidly metabolised and eliminated from the injection 
site, inducing a weak and transient local inflammatory reaction only. In contrast, mineral oils tend to reside at the injection site and are progressively eliminated by competent cells like macrophages as well as being partially metabolised to fatty acids, triglycerides, phospholipids or sterols. Bollinger et al. (15) demonstrated that in rats and squirrel monkeys 30\% of the mineral oil disappears during the first month and the majority of the oil found outside the injection site is in the liver and fat tissues in the form of phospholipids and fatty acids.

Generally, water-in-oil emulsions (W/O) are recommended for bovine, small ruminants, poultry and fish when long term immunity is required. In the case of foot and mouth disease, mineral oil based emulsions can protect bovines for one year with one vaccination whereas formulations based on aluminium hydroxide required two boosts or more. Even if some local reactions occur, W/O emulsions can be used when the protection against specific diseases as compared to other formulations or other routes of administration, is enough to justify some side effects. This is the case for fish vaccines against furunculosis, where the procedures can be limited to one injection as the protection is maintained during the whole growing period. W/O emulsions also allow reduction of the vaccine dose or the antigen concentration. W/O formulations can also enhance cellular immune responses. Vaccination of sheep against heartwater with W/O formulations enhances protection against challenge and are well tolerated. Miglyol 840-based (medium-chained triglyceride) vaccines containing Newcastle Disease and Infectious Bronchitis (IB) virus showed no local reactions at all, nor any vaccine residues, except for the W/O type of emulsion, which showed some traces of the inoculum. In contrast, equivalent vaccines containing mineral oil showed moderate local reactions at the injection site 12 weeks after inoculation when monitored by post-mortem macroscopic inspection (59). Similarly, Fukanoki et al. (43) detected cyst formation, granulomatous reaction and abscesses at the injection site 8-16 weeks after administration of oil adjuvanted vaccines prepared with various liquid paraffins in chickens. The vaccine with liquid paraffin mainly consisted of $\mathrm{n}-\mathrm{C} 16 \mathrm{H} 34 \sim \mathrm{n}-\mathrm{C} 20 \mathrm{H} 42$ and induced less severe problems due to adverse local reactions such as inflammatory responses and persistent residual oil.

Water-in-oil-in water emulsions (W/O/W) are of interest for their low viscosity and their ability to enhance both short and long term immune response. In foot and mouth disease, such formulations are able to protect swine as well as bovines against the disease only four days after vaccination which can be very useful in case of outbreak. However, multiphasic emulsions can also induce long term immunity and protect bovines against haemorrhagic septicaemia for one year after only one vaccination. Those based on mineral oil are recommended for swine, however, with reactive antigens it is preferable to avoid vaccination of fattening pigs as carcass blemish can be caused. Oil-in-water emulsions (O/W) are very fluid, well tolerated and induce strong short term immune responses. The oil phase ratio is very low, between 15 and 25\%, which partly explains their safety. Emulsions based on mineral oil can be safely used for fattening pigs in order to enhance antibody responses against bacterial or viral infection but also the potency of live vaccine like pseudorabies vaccine.

Vaccines for pets and horses must not induce any local reactions and then $\mathrm{O} / \mathrm{W}$ emulsions based on non mineral oil are adapted. Water dispersed liquid nanoparticles (10 to $500 \mathrm{~nm}$ ) combined with an immunostimulating compound is an interesting new adjuvant concept (socalled "immunosol" adjuvants) (8). Trials in swine against atrophic rhinitis or pleuropneumonia demonstrated that such formulation could enhance immune response without inducing local reactions $(87,88)$ and vaccination of bovine against anaplasmosis gave $100 \%$ protection. Moreover fish trials confirmed their good efficacy and safety and various trials in pets and horses are ongoing (8). 


\section{- Conclusions and perspectives}

There is no universal adjuvant and there is always a trade-off between safety and efficacy (8). Also, the adjuvant must be adapted to the target species, the antigens, the desired type of immune response, the route of inoculation, and the desired duration of immunity.

Water in oil (W/O) emulsions induce strong, long term immunity, however can sometimes induce local reactions with reactive antigens. Non mineral oils are well tolerated but less efficient with poor immunogens. Multiphasic (W/O/W) emulsions can induce short and long term immune responses and oil in water (O/W) emulsions are well tolerated and induce a short term immune response. Bovine and chickens can be vaccinated with W/O emulsions whereas swine generally require well tolerated adjuvant like O/W emulsions. Also, the antigen type will influence the selection. Mineral oils can be used when non reactive antigens like purified proteins or synthetic peptides are used. Non mineral oils are preferable with more reactive antigens. $W / O / W$ and $O / W$ can be used with live or DNA vaccines. Adjuvants must be able to enhance humoral or cellular mediated immunity according to the mechanism of protection against the disease. W/O emulsions are able to induce cellular response. W/O/W or O/W enhance humoral responses but have also been associated with enhancement of cellular responses. The duration of immunity has also to be considered and the selection of the adjuvant is different if short or long term immunity is required. The route of inoculation is also important, e.g. subcutaneous and intramuscular administration of the same vaccine formulation can give different immune responses. New generations of oils and surfactants may allow the development of stable safe and fluid emulsions $(8,26)$.

\section{Molecularly defined adjuvants: Toll-Like Receptors and the use of PAMP agonists as adjuvants in farm animals.}

As described above the innate immune response to pathogens provides a rapid early reaction to host invasion. This response initiates a range of inflammatory reactions through the expression of signalling proteins by infected and antigenpresenting cells. Proteins such as interferons, cytokines and chemokines mediate this activation as well as the chemo-attraction of a number of cell types including macrophages, lymphocytes, polymorphonuclear leukocytes and mast cells. This in turn paves the way for the development of the adaptive immune response and influences the development of antibody and cell-mediated responses. Whilst the innate immune response has evolved to enhance the survival of animals in the face of microbial invasion, it can itself result in damage to cells and structures within the host. Indeed, chemokines have been associated with autoimmune and cardiovascular disease in domestic animals (reviewed by Gangur et al.(44)), and many viruses encode genes that mimic chemokines or their receptors (111). Unsurprisingly the control of the innate immune system occurs early in the recognition process and is provided by groups of receptor proteins both at the cell surface and intracellularly that detect pathogens through engagement with integral pathogen structures known as pathogen-associated molecular patterns (PAMP). Examples of PAMPs are cell wall components for bacteria or particular nucleic acid structures unique to viruses such as double-stranded RNA $(33,96,141)$.

A key component of this pathogen detection system is the toll-like receptor (TLR) family whose members have been identified throughout the animal kingdom. A principal benefit for the evolution of this system is economy. A relatively small number of TLR, and other receptors including NOD-like and RIG-I receptors (reviewed by Creagh and O'Neill (24)) are able to detect a large range of pathogens at locations where pathogen-cell interactions can take place i.e. the cell surface, within endosomes and within the cell cytoplasm. The identification of such receptors and their agonists provides an opportunity to develop vaccine strategies that both enhance and focus the immune response in ways that are 
beneficial to the animal. In contrast to the TLR family, homologues for NoD-like and RIG-I-like receptors have not been identified in large farm animals. A key feature of the TLRs is their conserved structure. Each mature TLR can be divided into three functional domains (12); an ectodomain that is dominated by a continuous series of leucine-rich repeats (LRR) that forms the patternrecognition structure; a transmembrane domain that anchors the glycoprotein in the cell membranes and a Toll IL-receptor (TIR) domain that forms the cytoplasmic signalling domain. Specific PAMP recognition is through the LRRs of which there are between 16 and 28 within the ectodomain. Individual LRRs typically have a structure of LxxLxLxxNxL in which "L" is Leu, Ile, Val or Phe and "N" is Asn, Thr, Ser or Cys (extensively reviewed in Matsushima et al. (101). TLR3 provides a useful example of the features of this family of receptors. It is associated with endosomal membranes with the ectomain directed to the lumen of the endosome itself. TLR3 binds double-stranded RNA (3) and is a key receptor for the detection of RNA viruses $(100,102)$. The crystal structure of human TLR3 ectodomain has been solved at 2.1 angstroms and reveals a horseshoe-shaped molecule. The structure is heavily glycosylated with a single glycosylationfree surface that could bind ligands, and the conserved segments provide a likely site for homodimer formation (23). Complete TLR3 coding sequences have been identified in a range of large veterinary animals including cattle (NM 001008664; 21), pig (DQ647698) and horse (DQ266434). A partial sequence for sheêp has also been obtained (AY957614; 104). Alignment of human and bovine TLR3 (Figure 4, Suppl. info.) demonstrates the high degree of sequence homology suggesting a conservation of function among higher mammals. This also implies that TLR agonists (discussed below) that have been developed in small animal models should engage TLRs in larger animals although this must be tested empirically for both toxicity and efficacy. Certainly bovine macrophages and dendritic cells produce nitric oxide (NO) and cytokines in response to some common TLR agonists including lipopolysaccharide, poly (I:C) RNA and CgG-DNA (157) .

Concerning TLRs in farm animals, there is growing evidence that they are actively engaged in response to infection (158). In cattle, specific increases in TLR2 have been observed during mastitis infection (46) and porcine macrophages up-regulate TLR2 and 6 in response to infection with Mycoplasma hyopneumoniae (110), a major contributor to endemic pneumonia within swine. Many innate response genes, including TLR3, are activated in newborn calves following bovine rotavirus infection (2). However, there is further evidence of pathogen subversion of this system. TLR2 detects peptidoglycan (Table 1), a major component of bacterial cell walls including Mycobacterium spp. However, Mycobacterium bovis may use this to enhance uptake into phagocytes. Bovine viral diarrhoea virus (BVDV) infection has been shown to modulate TLR expression in bovine macrophages (41) and in bovine peripheral blood monocytes (90), influencing the production of $\mathrm{NO}$, TNFa production and type 1 interferon gene expression.

Can the TLR system be used to enhance veterinary vaccines? Engagement of TLRs activates at least two signalling pathways (11) that lead to the induction of antimicrobial genes and inflammatory cytokines (58). Among these are the type 1 interferons, tumour necrosis factor-alpha and interleukin-6. This suggests that inclusion of a TLR agonist within a vaccine preparation will induce a local inflammatory reaction and therefore fulfil the primary role of an adjuvant. TLR agonists also have the capacity to influence the development of the adaptive immune response, probably through recruitment and engagement of dendritic cells $(58,159)$. Currently such agonists are being used as topical antiviral agents in humans $(7,14)$ and are being included into vaccine vehicles for in vivo use (163). Indeed, one company (invivoGen) is offering a mouse TLR Agonist Kit containing an agonist for each class of TLR. Despite a number of setbacks in the field of human vaccine development, approval has now been gained for the first alum based vaccine prepared in combination with a TLR agonist (MPL®, GlaxoSmithKline), named ASO4 and developed for use with a hepatitis B vaccine. 
The ability of TLR agonists to influence the adaptive immune system has obvious attractions for the development of vaccines against a number of infectious diseases of livestock and man. Addition of such agonists would primarily be used to increase the magnitude of the immunological response, whether antibody or cell-mediated. This might also enhance the development of immunological memory. Secondly, the formulation could sway the immune response towards a particular Th response and would be of specific interest to those developing animal vaccines against intracellular pathogens, e.g. bovine tuberculosis (Mycobacterium bovis) that need a Th1-like response to be counteracted efficiently. Thirdly, inclusion of a TLR agonist might reduce the response time between vaccination and protection. This would be particularly useful for reactive vaccination in response to outbreaks such as foot and mouth disease and bluetongue virus or where post-exposure prophylaxis is required i.e. rabies virus. Currently, most of what we know of the TLR system has been derived from the mouse model and their practical applications, unsurprisingly, are in the field of human medicine. However, the inclusion of TLR agonists in human vaccines heralds the way for use of such compounds in the veterinary field.

\section{Molecularly defined adjuvants: CpG oligonucleotides as PAMP adjuvants in pigs}

Certain short, synthetic unmethylated oligodeoxynucleotides (ODNs) containing CpG ( (5'cytosine-guanine $3^{\prime}$ ) dinucleotide motifs show a strong immunostimulatory activity towards murine B cells (81) emulating the immune stimulatory activity of bacterial DNA preparations (144) (see reviews by Krieg (82) and Klinman et al. (78)). Unmethylated CPG motifs occur much more frequently in bacterial and protozoan DNA than in vertebrate DNA and therefore represent a class of PAMPs. The immunostimulatory activity depends on the intracellular CpG specific Tolllike receptor 9 (TLR9) (47) with CPG being taken up by the cell by endocytosis (113). In humans B cells and plasmacytoid dendritic cells (pDCs) express TLR9 and are primary targets for CpG ODNs. The responsiveness of immature plasmacytoid dendritic cells, also called natural interferon producing cells to CpG ODNs has been confirmed with pig cells (49).

As originally shown by Krieg et al. (81) CpG ODNs have immediate (8 hours), highly sequence specific stimulatory effects on mouse spleen cell cytokine and IgM secretion. Methylation of cytosine as well as replacement of either C or G completely abolished activity. Also, two purine bases should flank the CpG motif at its $5^{\prime}$-end and two pyrimidine bases should be present at the $3^{\prime}$-end for optimal activity, i.e. PuPuCGPyPy. GACGTT was a preferred motif in mice (81) and multiple CpG motifs increased activity. These initial studies in mice have been followed up by studies in cattle, sheep, pigs, horses, dogs, cats and fish (see Mutwiri et al. (113). CpG motifs with optimal stimulatory activity differ between species, possibly reflecting differences towards the specific pathogens preferentially infecting these species. In cattle, Brown et al. (19) showed that Babesia bovis DNA stimulated bovine B cells to proliferate and to produce IgG, related to the presence of unmethylated CpG sequences in the DNA that could be mimicked by synthetic ODNs, one immunostimulating sequence being identified as AACGTT. In humans optimal sequences were ATCGAT (type D, phosphodiester, conforming to the PuPyCGPuPy rule) and GTCGTT (type K, phosphorothioate)(155)) ${ }^{1}$. In pigs the palindromic type D sequence ATCGAT in a 20-mer ODN, having a phosphodiester core flanked by phosphorothioates at both ends was one of the most active motifs (65). The high activity of ODNs with phosphodiester cores and phosphorothioate $5^{\prime}$ and $3^{\prime}$ ends (chimeric ODNs) is a general finding with type D ODNs which are further enhanced by poly G stretches at both ends of the ODN

\footnotetext{
1 Type $\mathrm{D}$ and $\mathrm{K}$ ODNs (155) are also called type A and B, respectively (84).
} 
(84). Type $\mathrm{K}$ is optimally active as all-phosphorothioate molecules often containing multiple CpG motifs and with no demand for poly G motifs (82). In contrast to what has been demonstrated in sheep (16) the cytokine response of pig lymph node derived cells was found to be lower than that of pig PBMC (27), possibly linked to a lower constitutive TLR9 expression and a lower frequency in pigs of IFN-alpha producing cells in lymph node cells compared to PBMCs.

Immunostimulating CPG ODNs generally induce Th1-like responses characterized by IL-1, IFN- $\alpha$, TNF- $\alpha$, and IL-12 production and in some cases IFN- $\gamma$ and IL-6, generating cytotoxic T cells $(82,155)$. CPG ODNs can even shift an ongoing Th2 response into a Th1 response (113). As Th1-type adjuvants CpG ODNs are potentially useful in vaccines against intracellular pathogens, including viruses. It is also of great interest that CpG can work through mucosal routes of administration boosting mucosal responses $(95,115)$.

In vivo, a short half-life and adsorption by non-relevant tissue are limiting factors for the use of CpG ODNs. Natural backbone (phosphodiester) ODNs are degraded within minutes, however inclusion of phosphorothioate backbones increase plasma half-lives to up to 60 minutes and with tissue half-lives around 48 hours, as shown by studies in mice (113). Relevant delivery may be enhanced with targeting/delivery vehicles, e.g. transfection reagents, and/or by increasing concentration in the relevant tissue by increasing dose and/or prolonging release. Furthermore, as with DNA vaccines (152), the efficiency of CpG ODNs depends on efficient translocation of DNA into cells. This can be achieved in a number of ways using traditional adjuvants, with liposomes and polymer-based particles also potentially useful. In a recent study in cattle (80) combinations of CpG ODN, indolicidin and polyphosphazene were tested for ability to increase immunogenicity of hen egg white lysozyme and results indicated a humoral and cellular immunity enhancement both by complex formation between adjuvant and antigen and by the ability of polyphosphazene to increase the cytokine inducing abilities of CpG ODN and indolicidine. Humoral and cellular immunity was increased to the same level as by the oil-in-water adjuvant Emulsigen ${ }^{\circ}$. It is generally found that antigen specific immunogenicity may be augmented by binding the CpG ODN to the antigen or maintaining close contact between antigen and CPG ODN in other ways (78).

Inter-individual variability in responses to CpG ODN has been a frequent finding in outbred populations which may indicate that CpG sensitivity is partly genetically controlled (49, 65, 103, 113, 156).

CpG ODN, - as the only adjuvant sofar- was found to significantly increase both cell mediated immunity and humoral responses against PRRSV in pigs, and also protective efficacy in challenge models as reviewed by charerntantanakul et al. $(22,95)$. Subcutaneous injection of a K-type ODN with multiple phosphorothioate CPG motifs resulted in dose-dependent significant increases in PRRSV-specific antibody titres, MHC-II expression by PBMCs, IFN-gamma secretion upon antigenspecific stimulation of PBMCs in culture and in protection against disease and death (95). The "reverse" GpC analogue was much less active.

Our own data (Sorensen et al. unpublished and Figure 4, Suppl. info.) show that type D CPG but not its "reverse" control ODN (GpC) are able to induce several cytokines in pig PBMCs while a more type K-like ODN is active both in its CpG and its GpC form and with increased induction of IL-6. van der stede et al. (151) also found the activity of a CpG and its GpC analogue to be similar upon immunization of pigs with ovalbumin using a high intramuscular dose of $500 \mu \mathrm{g}$ ODN.

CPG ODNs were also found to increase protection against experimental infection in pigs with the parasite Toxoplasma gondii when injected in combination with 
tachyzoites (83). CPG ODNs provided better protection and led to higher serum anti-parasite antibody levels in comparison with Freund's incomplete adjuvant. The highly active ATCGAT palindrome defined by Kamstrup et al. (65) was found to increase the efficiency of a DNA vaccine against Pseudorabies virus infection in pigs, increasing protection, and humoral as well as cell-mediated immunity (30). The same vaccine was investigated by the oral route (95) where oDNs were found to increase systemic and mucosal antigen-specific antibody responses. Mixed phosphorothioate/phosphodiester backbones induced stronger IFN-gamma and proliferative responses than phosphorothioate-only oDNs while antibody responses were similar. In another study cell-mediated, Th1-type cytotoxic immunity against Hepatitis C virus was achieved by immunization with a plasmid coding for the NS3 protein of Hepatitis C, followed by boosting with recombinant NS3 mixed with CpG and Quil A (both in mice and pigs) (162).

As shown by Kekarainen et al. (73) CpG motifs in viral genomes (in this case porcine circovirus type 2, PCV2) can also modulate host immune responses in a context dependent way; for example, CpG motifs originating from the PCV2 Rep gene were superior in inhibiting IFN-alpha production induced in recall responses with pseudorabies virus compared to other viral CpG motifs.

Quite another use of CpG-based immunostimulators is for immediate, and transient, protection against infection, which was demonstrated for a range of bacteria, viruses and protozoa (reviewed by Klinman et al. (77) and Mutwiri et al. (113). Irrespectively of inoculation route, CpG ODNs protected mice against lethal doses of the intracellular bacteria Listeria monocytogenes and

Francisella tularensis, provided the ODNs were administered prior to infection (optimally 3-14 days before, and weaning off at 21 days before). If oDNs were repeatedly injected, administration of the specific pathogen within the protected time frame led to the creation of prolonged pathogen-specific immunity (77). For "slow" pathogens as e.g. Leishmania monocytogenes protection could be achieved post-infection (77). The effect of mucosal delivery (intrapulmonary) of CPG ODNs was studied in sheep and it was found that a transient (lasting 2-5 days) systemic acute phase and antiviral response took place, the effect of the ODN being highly increased by including an oil-in-water adjuvant (Emulsigen®) (115). These effects were also seen upon sc as well as intratracheal administration. In rainbow trout immunized with a combination of different salmonid rhabdovirus DNA protection against infection lasted for 4 days after vaccination and was apparently related to type I interferon induction (35). However, these effects are apparently not due to CpG as the involvement of TLR9 could not be demonstrated (118), - instead the effect could be caused by the expressed rhabdovirus glycoproteins (76).

Such CPG ODN mediated immediate innate responses do not rely on specific immunity, and are not antigen dependent. The protection is short-lived (days), unspecific and has no memory component. This has relevance for peri-exposure prophylaxis of herds of production animals e.g. against Foot-and-Mouth disease outbreak in neighbouring herds as was investigated in mice in which protection against challenge with 5 out of 6 different serotypes of foot-and-mouth disease virus (FMDV) was achieved (66). The protection lasted for 14 days. and, rather surprisingly, was also seen when ODN was administered simultaneously with or up to 12 hours after inoculation of the virus. Post-virus administration however had little effect on viraemia. For practical use as a means of FMDV control both protection against disease and inhibition of virus secretion are pivotal. This protection strategy does not interfere with monitoring through analysis of antibodies in blood samples (serodiagnosis). However, more recent data indicate that CpG has no effect on innate mediated early protection against FMDV promoted disease in pigs (4), in contrast to the findings in mice. CpG ODN mixed with Emulsigen (B and injected intramuscularly, did induce INF- $\alpha$ for at least 4 days after injection, however did not protect pigs against disease at FMDV challenge 2 days after a combined FMDV vaccine and CPG injection. Furthermore, with this 
specific vaccine, CPG did not increase the protective effect of the vaccine as seen when challenge was performed more than 7 days after vaccination. This underlines the difficulties in interpreting effects of this type of adjuvants between species.

As small, stable, and easily synthesizable molecules CpG ODNs hold promise as molecular adjuvants. Their strongly Th1-biased immunostimulatory activity, without the adverse effects frequently seen with traditional Th1 inducing adjuvants (mineral oil adjuvants, see above) complements the Th2-skewed activity of generally approved aluminium salt based adjuvants. They have potential for stimulation of mucosal immunity and show immediate activity against intracellular infections. The challenge is to define CpG ODNs with optimal activity in the species of interest, and being broadly active between individual animals. More knowledge is needed to define the optimal combination of antigens and ODNs, to establish practical administration routes as well as to elucidate long term adverse effects related to the possible generation of anti-DNA autoimmunity.

\section{Molecularly defined adjuvants: Endogenous mediators for targeting lymphocytes to mucosal surfaces. \\ Retinoic acid}

Efficient induction of mucosal immunity most often employs vaccination at mucosal sites as parenteral immunization generally is ineffective at generating mucosal immune responses. This relates to the compartmentalization of mucosal and systemic immune responses, which is mainly based on the selective expression of homing receptors on lymphocytes. These receptors target effector and memory cells to specific ligands expressed in the extralymphoid site of the original antigen encounter (106). Thus, lymphocytes primed in the gut associated immune system, such as Peyer's patches or mesenteric lymph nodes express the integrin $\alpha 4 \beta 7$ and the chemokine receptor CCR9 and subsequently migrate to the small intestinal mucosal tissues where their ligands, mucosal addressin cell adhesion molecule-1 and CCL25, respectively, are expressed by postcapillary venules and intestinal epithelial cells, respectively. In contrast, lymphocytes primed in peripheral lymph nodes express ligands for vascular P- and E-selectins and the chemokine receptors CCR4 and/or CCR10. Local resident dendritic cells (DC) play an important role in instructing naïve lymphocytes to express the appropriate homing receptor profile $(63,105,138)$. For example, DC isolated from Peyer's patches or mesenteric lymph nodes induced $\alpha 4 \beta 7$ and CCR9 expression in cocultured $\mathrm{T}$ or $\mathrm{B}$ cells whereas DC isolated from peripheral lymph nodes promoted the expression of $\mathrm{P}$ - and E-selectin ligands. The ability of intestinal DC to confer gut tropism to $T$ cells may not necessarily be the attribute of a distinct, tissue restricted DC subset $(63,105)$. Rather, the local tissue (cytokine) environment and microbial signals play a dominant role in shaping the mucosal imprinting capacity of DC $(31,32,68)$.

In addition to their ability to promote gut-tropism of $\mathrm{T}$ cells mucosal DC are characterized by their capacity to induce IgA responses and by their preferential secretion of the cytokines IL-10, TGF- $\beta$ and IL-6 (55).

Interestingly, the ability of intestinal DC to promote lymphocyte targeting to the gut was linked to their unique expression of retinoid hydrogenase enzymes which convert dietary vitamin A to retinoic acid. Retinoic acid is a natural bioactive metabolite of vitamin A which regulates a broad range of biologic processes including inflammation, and cell differentiation and proliferation through binding to specific nuclear retinoid receptors present in many cell types including $T$ and $B$ cells (10). With regard to lymphocyte differentiation, retinoic acid was shown to directly up-regulate $\alpha 4 \beta 7$ and CCR9 expression on $\mathrm{T}$ cells (56). In addition to this modulation of the homing properties of $T$ 
lymphocytes to mucosal sites, gut DC-derived retinoic acid was also identified among other factors as an important inducer of IgA secretion in B cells (106). Recent experiments performed also in large animal models investigated the potential of peripheral DC to be modulated towards a mucosa-type DC. This would enable the induction of mucosal immune responses after parenteral administration of antigen and some support for the feasibility of this has been obtained (132). Porcine monocyte-derived DC pre-treated with the vitamin A derivative all-trans retinoic acid (RA) acquired several attributes characteristic of mucosal DC, including (i) secretion of the cytokines TGF- $\beta$ and IL-6, (ii) the capacity to induce IgA responses and (iii) the ability to induce expression of mucosal homing receptors in co-cultured lymphocytes (132). Transwell experiments separating the cell populations in an in vitro porcine co-culture model revealed that RA-treated monocyte-derived DC mediate their effects through soluble factors rather than through cognate receptor interaction with lymphocytes. Although no IL-10 was detectable in supernatants from RA-treated monocytederived DC, RA was found to induce TGF- $\beta$. Addition of a pan-TGF- $\beta$ neutralizing monoclonal antibody reduced the capacity of the RA-treated monocyte-derived DC to induce integrin $\alpha 4 \beta 7$ up-regulation in co-cultured lymphocytes significantly. Up-regulation of CCR9 mRNA induced by RA-treated porcine monocyte-derived DC was not affected by the presence of the TGF- $\beta$ neutralizing monoclonal antibody. Thus, $\beta 7$ integrin and CCR9 expression in this large animal in vitro model appear to be differentially regulated similar to what has been described in the mouse system $(63,105)$.

The ability to induce specific IgG and IgA responses was also investigated using food and mouth disease virus (FMDV) as antigen (132). It could be shown that RA treated monocyte-derived porcine DC are potent inducers of specific IgG and IgA responses. Similar experiments in the presence of a RA receptor antagonist revealed that $\alpha 4 \beta 7$ integrin and CCR9 mRNA expression was suppressed, but IgA production remained unchanged suggesting that a different mechanism contributes to these effects on $\mathrm{T}$ and $\mathrm{B}$ lymphocytes.

The role of RA as a mucosal immune modulator would be consistent with the location of mucosal DC in the vicinity of RA-producing intestinal epithelial cells (85) and the autocrine production of RA by intestinal DC. Initial in vivo immunization experiments revealed that the application of RA in a vitamin $A$ deficiency model in rats enhanced the antibody response to tetanus toxoid (28). The transcutaneous application of RA with cholera toxin and whole inactivated influenza virus augmented the intestinal anti-influenza virus response compared with a cholera toxin virus combination (136). Whether migration of peripheral DC to mucosal inductive sites or the imprinting of mucosal homing receptor expression in local draining lymph nodes account for these effects need to be investigated in future studies $(13,36,132)$.

These findings suggest a novel role for RA as a mucosal immune modulator targeting DC, which is of particular interest for adjuvant and also nutritional applications.

\section{Interferons}

Dendritic cells (DC) and particularly the interaction between conventional 'myeloid' DC (CDC) and plasmacytoid DC (pDC) are important for efficient immune defence functions (pDC are also known as natural interferon producing cells). The host immune system is often manipulated by viral pathogens infecting DC. The manner by which different viruses interfere with DC function depends on both the virus and the subset of DC involved. The recognition of viral nucleic acids by pattern recognition receptors (PRRs) is the first step in inducing the innate immune system. Type I interferons, central mediators in antiviral innate immunity, along with other cytokines and chemokines, disrupt virus replication. Recent studies indicated at least two distinct pathways for type I interferon 
induction by viral infection, one mediated by retinoic acid-inducible gene-I (RIG-I) and one mediated by melanoma differentiation-associated gene 5 (MDA5).

In addition to their direct antiviral activity, type I interferons also posses major immunomodulatory abilities. In vivo experiments showed that type I interferons can potently enhance humoral immunity and promote isotype switching (89). Type I interferons secreted by pDC have been shown to induce B-lymphocytes to differentiate into antibody producing plasma cells and to be necessary for the production of both specific and polyclonal humoral immune responses after influenza virus infection (124). With regard to an adjuvant effect in vaccination experiments, type I interferons were shown to have potent activities when co-administered with inactivated vaccine preparations applied through the parenteral route $(60,149)$. Humoral IgG and IgA levels were significantly elevated in a dose-dependent manner when interferon-alpha was co-administered with an inactivated influenza vaccine. In contrast, intraperitoneal application of interferon-alpha at a distant site of the vaccination antigen rather decreased the humoral immune response (149). Characterization of the cell population activated by the interferon-alpha co-administration revealed that populations corresponding to $\mathrm{CDC}$ and $\mathrm{pDC}$ were involved. Therefore, trafficking of antigen presenting cells towards the site of vaccination may explain at least in part the mechanism underlying the adjuvant activity of interferon-alpha when co-administered with inactivated vaccine preparations (149).

To investigate the species specificity of commercially available interferonalpha human (HRT-18, Panc), simian (Vero), and bovine (MDBK) cells were treated with commercially available human recombinant interferon-alpha expressed in Escherichia coli (Sigma-Aldrich ${ }^{\circledR}$ ). Reactivity of the cells was tested by the induction of the antiviral Mx protein using the anti-Mx antibody M143 (39). As shown in Figure 6 (Suppl. info) the human recombinant interferon induced $\mathrm{Mx}$ protein synthesis in human, simian as well as bovine cells in a dose-dependent manner. Interestingly the strongest induction was observed in the cells of bovine origin, which should be further investigated.

\section{Well-defined carrier/delivery systems: Particulate antigen delivery systems for mucosal immunity.}

The delivery of purified antigens by encapsulation into particulate, non living, systems offers a range of advantages such as 1) enhancement of the immunogenicity of soluble antigens, 2) increase of the antigen uptake, 3) protection of the antigens, 4) reduction of the antigen dose, and 5) control of antigen release. Another major advantage is the capacity for mucosal antigen delivery. This route is the most relevant to trigger protection since almost 90\% of all pathogens, regardless of which species, enter and initiate infection at mucosal surfaces (45). IgA, the main mucosal immunoglobulin, cannot be induced by parenteral inoculation and thus systemic (parenteral) vaccination only triggers incomplete protection against mucosal infections, although partial transfer of IgG1 and IgG2 from serum into the lung was demonstrated in cattle (17). However, soluble antigens are poor immunogens by oral or nasal routes and adjuvants or delivery systems for these kinds of antigens are needed to induce mucosal immune responses (25). Mucosal immunization elicits strong mucosal immune responses even in remote mucosal sites (the existence of a common mucosal immune system has been confirmed in large animals (133), and in addition a systemic immune response - depending on the size of the particles.

The advantages of particulate antigen delivery systems for mucosal immunization include 1)protection of antigen against the gastrointestinal environment (acid and proteolytic enzymes), 2) enhancement of antigen translocation to the mucosaassociated lymphoid tissue, 3) ease of delivery via the oral or intranasal route. A variety of particulate systems has been developed; here we will focus on microparticles and liposomes. 


\section{Microparticles: Uses in ruminants.}

Microparticles (MP) can be derived from different polymers including polylactide-coglycolide (PLG) (Figure 7, Suppl. info.), alginate, and starch or other carbohydrate polymers. Compared to PLG MP, the manufacture of which requires the use of organic solvents that may alter antigenic epitopes, alginate MP are produced using mild conditions $(45,126)$ using an inexpensive, non-toxic, naturally occurring polysaccharide that is also biodegradable. Alginate MPs are compatible with a variety of antigens, have proved useful to circumvent the maternal antibodies in vaccination of young animals (75), and improve capture of DNA by antigen presenting cells (APC) (152). A direct adjuvant role for the alginate has also been suggested (126). Biodegradable MP were originally developed for oral delivery (126), however, although demonstrating high efficacy in small animal models, few of them were tested in large animals.

For parenteral delivery, a single injection in cattle of a Staphylococcus aureus lysate encapsulated in biodegradable PLG microparticles (Sta-MP) was

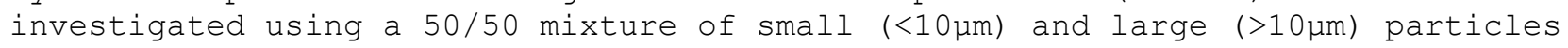
emulsified in Freund's incomplete adjuvant (FIA)(117). This resulted in an antibody response similar to that obtained when emulsifying the antigen in FIA, although with a lower level, likely due to the slow release of the antigens. The Sta-MP-elicited antibodies supported phagocytosis at ahigher level than unencapsulated antigens. It was suggested that the small MP (<10um) were taken up by APC while the larger $(>10 \mu \mathrm{m})$ served as antigen depot slowly releasing the antigen over an extended period of time. It can therefore be envisaged that a long-term functional antibody response can be elicited by a single injection. Another study reported on the delivery of naked DNA plasmids encoding protective foot-and-mouth disease (FMD) antigens and ovine GM-CSF in sheep after formulation in PLG MP, compared to administering the plasmids only, plasmids in alum or in lipofectin, using intradermal and intramuscular injection (114). The formulation in MP proved to be the only one able to trigger an FMD-specific cell-mediated immune response. The level of protection against FMDV challenge was similar to that obtained by a conventional vaccine. In contrast, no immunity was induced in sheep by the nasal route, even in the presence of the $E$. coli labile toxin. These findings confirm that PLG MP can be used for DNA vaccination by the parenteral route.

The efficacy of MP in inducing mucosal immunity was evaluated in cattle and it was demonstrated that after oral delivery, particles less than 5 m were rapidly translocated to the lymphatics and disseminated to the systemic lymphoid organs while MP greater than $5 \mu \mathrm{m}$ remained in the Peyer's patches with a very slow translocation to the efferent lymphatics $(75,164)$. Therefore, small MP may induce a systemic as well as a mucosal immune response whereas larger MP may only induce a local response. The efficacy of alginate or PLG-MP to elicit a mucosal immune response against model antigens such as ovalbumin (OVA) and porcine serum albumin (PSA) was also studied in cattle. In one study, OVA was encapsulated in alginate MP with 70\% of the MP having a diameter less than $10 \mu m$ and 30\% less than 50um (17). These OVA-MP were then entrapped in larger alginate macrospheres (4-5 mm) and placed in gelatine boluses for oral delivery to cattle. This system has been shown to release the encapsulated material into the lower intestinal tract. Compared to control animals, cattle receiving two oral regimens (each including five daily doses of $5 \mathrm{mg}$ OVA) with a 2-week interval, presented a significantly higher number of anti-OVA IgA antibody-secreting cells (ASC) in their bronchoalveolar lavages (BAL). This study also showed that priming by the subcutaneous route with OVA greatly enhanced the mucosal response with higher numbers of anti-OVA IgA, IgG1 and IgG2 ASC in the BAL as well as anti-OVA IgG1 ASC in the blood (17). This indicates that the antigen was well protected by alginate macrosphere encapsulation and able to trigger an IgA response even in the pulmonary mucosal system after oral administration. Also, 
oral boosting with an antigen encapsulated in MP enhanced the protection obtained by subcutaneous vaccination with the same antigen.

A comparison between oral and intranasal delivery in cattle of pig serum albumin (PSA) contained within alginate MP (126) did not lead to the same conclusions as in the above study as it was found that only intranasal delivery led to a PSAspecific humoral response, but with IgGl being the only significant

immunoglobulin isotype in serum, saliva and nasal secretions and with no cellular response and no statistically significant anti-PSA IgA response. The lack of a clear mucosal IgA response is surprising, however 64 of particles were less than $2 \mu \mathrm{m}$ and only 5\% were bigger than $5 \mu \mathrm{m}$ which is different from the above study. It is possible that in cattle this range of sizes allows the particles to bypass the local lymphoid tissues and go directly to the draining lymph nodes. Intranasal delivery was also investigated in cattle by Kavanagh et al. (72) using OVA-containing PLG MP less than 2.5um. The objective was to define the optimal dose of OVA and timing of the booster inoculation to elicit an IgA response. A significant, but moderate, mucosal IgA and serum IgG response was achieved with $1 \mathrm{ml}$ of PLG-MP containing $1 \mathrm{mg}$ of OVA administered into each nostril. The determination of the timing of the booster inoculation did not result in clear cut differences, although a boost at 3 weeks showed higher overall OVA-specific IgA levels. This finding might be due to sustained release of the antigen which may give unpredictable results. Nevertheless, this sustained antigen release allowed the generation of a prolonged IgA response up to 5 months following an intranasal boost given at week 5 .

These studies illustrate that mucosal immunization is more challenging than parenteral delivery. Critical factors include the MP size and composition as well as the protocol and anatomical site for the mucosal delivery. In ruminants, the gut-associated lymphoid tissues (GALT) is located as patches in the jejunum, ileum, colon and rectum with $\mathrm{M}$ cells identified in all sites (92). However, internalization of latex beads (250 and $610 \mathrm{~nm}$ ) was only demonstrated with $\mathrm{M}$ cells of the ileum and not with those of the jejunum (92). Concerning the nasalassociated lymphoid tissues (NALT), in ruminants, it is located in the nasopharynx, posterior to the opening of the Eustachian tube (92). Besides the NALT, the lymphoid tissues of the Waldeyer's ring are even more developed in farm animals. They guard the nasal (pharyngeal and tubal tonsils), oral (lingual, palatine and soft palatine tonsils) and auditory passage into the pharynx. M-like cells were identified in the pharyngeal and palatine tonsils of the sheep (92) and the function of the ovine NALT as a potent antigen sampling site has been demonstrated (139). Furthermore, in ruminants, other lymphoid tissues, such as the bronchus-associated lymphoid tissue (BALT), can be induced by antigen exposure (92). Thus all of these lymphoid tissues play a major role as active inductive mucosal sites. The anatomical localization of the intranasal immunization, depending on the particle size and delivery device, is thus also a critical point in triggering optimal mucosal responses. It will determine if the antigen-loaded MP will reach and be retained in the relevant tissues for sustained antigen release or be entrapped and rejected by the nasal mucus. To further characterize the uptake of alginate MP and their ability to trigger a mucosal response, in vitro experiments were performed in a sheep intestinal "loop" model $(75,112)$ using PSA as the encapsulated antigen. First, a comparative analysis was made between MP of less than $10 \mu \mathrm{m}$ and MP over $10 \mu \mathrm{m}$. The results revealed that only MP <10 um attached to the follicle-associated epithelium overlying the Peyer's patches within which M cells are contained, confirming previous observations made in mice and pigs (75). The uptake of the PSA-MP was confirmed by the presence of numerous PSA-specific antibody-secreting cells of IgG and IgA isotypes in the Peyer's patches (75). Induction of a systemic humoral response was also observed but no cellular response (112). Although no cell-mediated immune response was detected in these studies, there is evidence that MP can induce cellular immunity in mice following mucosal immunization with proteins and may preferentially induce a Th1 response (112). 
These findings demonstrate that MP with a diameter less than $10 \mu m$ can be an efficient antigen delivery system for oral immunization if they can reach the relevant mucosal lymphoid tissues where the cellular uptake takes place. Similarly, Rebelatto et al. (126) reported an old study demonstrating that in calves, tonsils could absorb resin particles of $1-5 \mu \mathrm{m}$ in diameter. Then, as described above, an optimal balance between differently sized MS should be defined to allow both mucosal and systemic immune responses and long term immunity. Appropriate delivery to the mucosal inductive sites is a critical requirement for vaccine efficacy.

\section{Microparticles: Uses in pigs.}

Since 1992, when Weng et al. reported on the protective effects of an oral microencapsulated M. hyopneumoniae vaccine against experimental infection in pigs (156), only a few studies had been published on the usability of microparticles for vaccine delivery in pigs. Some of these delivery systems remained unsuccessful or are largely untested for oral vaccine delivery in large animals $(92,112)$. Felder et al. (37) examined the feasibility of peroral immunisation with microencapsulated Escherichia coli and detached fimbriae to prevent enterotoxigenic E. Coli infections in pigs. Various MP formulations designed to deliver priming and booster doses were fed to new-born and weaned pigs. No significant serum IgA antibodies were induced and after peroral homologous challenge 19 days after the booster vaccination E. coli colonisation was not reduced.

The apparent discrepancy between results from small and large animals suggests that additional barriers may impede the local trafficking of MP throughout the GALT. Torche et al. (148) investigated the systemic immune response after administration to pigs of a model antigen (IgY), either in solution or encapsulated in PLG MP. A surgical experimental model ensured local delivery of IgY at different GALT locations including the intestinal lumen, in mesenteric lymph nodes and within Peyer's patches. It was found that PLG MP were able to elicit a combined serum IgG2/G1 response with a predominance of IgG1 when locally administered. PLG MP could be a potential oral delivery system for antigen, however these results further underline the difficulty associated with immunizing large animals like pigs.

During the last ten years, work has been performed on the targeting of MP to antigen presenting cells to improve their potency. Thus modified PLGA MP with specific ligands on their surface for increasing their cellular uptake have been investigated in vitro on pig alveolar macrophages $(145,147)$. An ex vivo assay was also performed on a pig ileal Peyer's patch segment to confirm the traffic of PLG MP throughout M cells (146). Brandhonneur et al. (18) studied cationic (poly-L-lysine grafted) PLG MP and ligands such as wheat germ agglutinin, mannose-PEG3-NH2 and arginine-glycine-aspartic acid grafted on PLG MP in this system and found their uptake by macrophages to be increased. However, the relative contribution of specific and non-specific uptake varied according to the ligands, and was dependent on the particle-to-cell ratio. Jiang et al. (62) describe the potential of mannosylated chitosan microparticles to target mouse macrophage mannose receptors. Non grafted chitosan microparticles were previously shown to be effective in pigs in inducing specific immune responses against Bordetella bronchiseptica (67).

\section{Liposomes: Uses in ruminants.}

Due to their flexibility with regard to size, composition, charge and bilayer fluidity as well as their ability to incorporate large amounts of antigens and a variety of hydrophilic or hydrophobic compounds, liposomes are interesting antigen delivery systems. In vaccine applications, their main functions are to protect the antigens from clearance in the body and to deliver the antigens to professional antigen-presenting cells (Figure 1). They are classically composed 
of natural, biodegradable, nontoxic and nonimmunogenic phospholipids in which antigen is either enclosed within the core, corresponding to an aqueous phase, or intercalated into the lipid layer $(9,54)$. Liposomes might be used as carriers for proteins, peptide-derived antigens and for nucleic acids encoding antigens (DNA plasmids, mRNA) or targeting genes (siRNA) (9, 51, 64). Liposomes may have natural adjuvant properties depending of their lipid composition. For example, an increase of IFN-Y secretion by murine spleen cells was observed ex vivo when phosphatidylserine is used as neutral lipid in liposome formulation (6). Liposomes can also influence antigen presentation. It has been described that an antigenic protein delivered by conventional liposomes was processed via the class II molecules of the major histocompatibility complex (MHC II) pathway, while MHC I presentation could be achieved with pH-sensitive liposome carriers (91). Also, liposomes can be made directly immunostimulatory by including microbial PAMPs. For example, antigen presenting cell activation through interaction with TLR or CD14 was reported when lipopolysaccharide (LPS) derivatives were added in liposome formulation (54). By optimizing the lipid composition and biophysical properties of liposomes, it is also possible to target specific tissues or cell-types. Several groups report that cationic liposome-encapsulated antigens are phagocytosed by dendritic cells to a much greater extent than anionic particles, inducing their activation and leading to increased efficiency of presentation to the immune system (40, 130,143) (Figure 8, Suppl. info.). The mechanism behind these differences in passive targeting of antigen presentation remains unknown. Active cell-targeting can be achieved by the use of engineered lipids. As an example, it has been observed that addition of mannosylated phosphatidylethanolamine, specifically recognised by mannose receptors, leads to specific delivery to CD1lct antigen presenting spleen cells after systemic injection (52). To target other cell-types, liposomes coated with immunoglobulin or Fab fragments have been developed. In this case, specific cell-attachment of "immunoliposomes" is a function of the affinity and avidity of the Ig towards a cell-surface marker (99). In addition, liposomes have been used widely for oral and intranasal delivery of antigens in mice. For this purpose, improved delivery was achieved by conjugation of the liposomes with recombinant $B$ subunit of cholera toxin or IgA $(45,164)$.

Very few liposome formulations have been used in veterinary medicine; this includes uses as a novel antitumor drug delivery system or vaccine for dogs and cats $(98,122,150)$. Tana et al. showed that cationic liposomes were efficient in promoting diphtheria toxin A-chain gene delivery in bovine leukemia virus infected cells after intratumoral injection (142). Subunit vaccines based on liposome-encapsulated antigenic protein have also been assessed. Subcutaneous immunisation against bovine herpesvirus type 1 with liposome-entrapped herpesvirus antigen and IL-12 has been reported to elicit induction of antigenspecific cellular and humoral immune responses (9). More recently, liposomal delivery of recombinant antigen has been described to enhance the immune response against Brucella abortus in mice (97). Assessment of intramuscular delivery in cattle of a liposome-based DNA vaccine against bovine viral diarrhoea virus was described by Harpin et al. (51). These authors reported that lipoplexes, formed by plasmid encoding the major glycoprotein E2 and conventional cationic liposomes were able to enhance the immune response compared to naked DNA.

A new generation of engineered liposomes holds promise for even more efficient immunostimulation. For example, immunization of cattle with recombinant major piroplasm surface protein from Theileria sergenti encapsulated by mannan-coated liposomes has been reported to be an efficient inducer of T-cell immune responses (64).

\section{Conclusions and perspectives}

There is considerable interest in mucosal routes of vaccination in livestock since they obviate the problems associated with injection, stress and handling of the animals and do not require trained personnel and as a large number of 
infections are of mucosal origin. Both microparticles and liposomes have proved efficient for mucosal vaccine delivery in small animal models (45). Their study in large animals is still at an early stage; however the results achieved warrant further experiments. Microparticulate delivery represents an efficient and cost effective vaccine strategy with particular relevance for developing countries. Oral delivery, the most attractive route for mucosal immunization of livestock, might be used to achieve mucosal immunity not only in the digestive tract, but also in the lungs. Even so, nasal vaccination may provide a practical alternative to the oral immunization because of its relative accessibility, high permeability of the local lymphoid tissues, less acidic pH and lower levels of enzymatic activity compared to the gut lymphoid tissues (139). This may be of particular importance in ruminants since orally administered antigens have to pass through the rumen before reaching the target GALT.

The studies reported above offer preliminary proof of concept that encapsulating antigens in particulate system protects the antigen, facilitates and controls its uptake either by antigen presenting cells or by the M cells of the nasal or intestinal mucosae and triggers an immune response. Further enhancement of mucosal immune responses may be obtained by optimizing the antigen dose, the size and composition of the particles, improving cell targeting, and by incorporating relevant adjuvants/immunomodulators. Particulate delivery systems can accomodate both antigens, immunomodulators and targeting molecules at the same time and the simultaneous presence of antigen, adjuvant and a targeted antigen presenting cell (APC) will efficiently enhance APC activation.

\section{Conclusions}

The development of novel safe, efficient and yet cost effective vaccine formulations is a great challenge, although a large panel of innovative strategies are being investigated and significant advances have been achieved. The majority of these studies are conducted in small animal (rodent) models and the translation of results from small to large animals is not a trivial task. Apart from a whole range of differences in the finer details of the molecular mechanisms and the physiology of the immune system between species there are also major differences related to general physiology that invites substantially different vaccine strategies and methods to be used, especially when considering mucosal immunization. There are also interesting differences in reaction patterns towards different types of PAMs, including CpG-containing DNA, possibly evolutionarily adapted to the spectrum of infections that commonly occur in a given species. Other variations in PAMP responsiveness are seen, for example there are major differences in responsiveness to lipopolysaccharides between species. On top of this there are a number of practical considerations related to production/rearing practices, economical concerns and animal "use" considerations (meat quality, fur blemishes etc.) that are not relevant for humans and for laboratory rodents.

Therefore, the potential of new vaccine formulation strategies for improving veterinary vaccines still remains largely unexploited, although there is a great need for needle free, cost effective, single shot vaccines triggering long lasting immunity in large animals, including livestock.

\section{Acknowledgements}

This work was supported by the EU Network of Excellence, EPIZONE (Contract No FOOD-CT-2006-016236). 


\section{Figure and Table legends}

Figure 1:

Schematic showing the possibility of incorporating various components with potential for vaccine delivery and efficacy into liposomes.

Table 1:

Summary of Toll-like receptor biology (agonists and cellular location)

Table 2:

Conventional adjuvants and their mode of action 


\section{Supplementary information:}

Figure 1, suppl. info.:

A: Physiology of the immune system showing the presence and distinct locations of pathogen/antigen encounter and display (DCs at infection site), antigen presentation and $\mathrm{T}-$ and $\mathrm{B}-\mathrm{cell}$ stimulation (activated DCs, lymph nodes) and return to site of pathogen localization of high numbers of highly specific Tand B-cells. Figure reproduced by kind permission from Bioconj. Chem. (Heegaard PMH, Boas U, Sorensen NS (2010) Dendrimers for Vaccine and Immunostimulatory Uses. A Review. Bioconjugate Chem 21: 405-418)

B: The innate and adaptive immunity domains depicting innate immunity as the provider of stimuli for the adaptive immunity to develop in specific ways (represented by Th1 and Th2 cells, respectively) with specific types of activity. Figure reproduced by kind permission from Bioconj. Chem. (Heegaard PMH, Boas U, Sorensen NS (2010) Dendrimers for Vaccine and Immunostimulatory Uses. A Review. Bioconjugate Chem 21: 405-418)

Figure 2, Supplementary information:

Subcutis, dog. Foreign lipid material eliciting piogranulomatous inflammatory reaction, mainly composed of macrophages, epithelioid cells and neutrophils.

Figure 3, Supplementary information:

Subcutis, cat. Post-vaccinal fibrosarcoma, characterised by highly pleomorphic fibroblasts, with high mitotic rate (arrowhead) intermingled with multinucleated giant cells (arrows), showing phagocytic activity.

Figure 4, Supplementary information:

Alignment of human (NM_003265) and bovine (NM_001008664) TLR3 sequences (a) and phylogenetic tree showing evolutionary relationship between avian and mammalian TLR3 (b) .

Figure 5, Supplementary information:

CPG ODN D19 (65) effects on pig PBMCs. The production of selected cytokines after overnight culture with either D19 (black boxes) or its variant in which the only change is that $\mathrm{CPG}$ is inverted to GpC (white boxes). For clarity all cytokines are depicted in the same figure. As detection limits vary they are depicted for each cytokine (dotted lines). Controls (cells cultured in the presence of medium only) always produced cytokines below the detection limit. Means and SEMs are shown for PBMCs from 6 animals.

Figure 6, Supplementary information:

HRT-18 (A), Panc (B), Vero (C), and MDBK (D) cells were incubated for $12 \mathrm{~h}$ in the presence of the indicated amounts of human recombinant interferon-alpha (concentrations between 100000 and 10 Units). Cells were dissolved in Laemmli buffer, separated on 10\% SDS-polyacrylamide gels, transferred to nitrocellulose membranes and subsequently stained with monoclonal antibody M143 kindly proved by G. Kochs (University of Freiburg, Germany). The secondary antibodies were goat anti-mouse IgG coupled to HRP.

Figure 7, Supplementary information:

(a) Scanning electron micrograph showing PLG-OVA microspheres (bar represents $5 \mu \mathrm{m})$. (b) Single microsphere after 4 weeks in PBS, showing large fissure in polymer surface (bar represents $1 \mu \mathrm{m}$ ) (reproduced by permission from Kavanagh et al. (72), License number: 2085771131023)

Figure 8, Supplementary information: 
Interaction between liposomes and murine dendritic cells: Confocal microscopy analysis of the interaction between murine bone marrow-derived dendritic cells and various liposome (bright) formulations. A and C: Anionic liposomes; B : Mannosylated liposomes; D : Cationic liposomes. Bars: 10 um. (reproduced by permission from Foged et al. (41), License number: 2112511301139) 


\section{References}

1. Aguilar JC, Rodriguez EG (2007) Vaccine adjuvants revisited. Vaccine 25: $3752-3762$

2. Aich P, Wilson HL, Kaushik RS, Potter AA, Babiuk LA, Griebel P (2007) Comparative analysis of innate immune responses following infection of newborn calves with bovine rotavirus and bovine coronavirus. J Gen Virol 88: 2749-2761

3. Alexopoulou L, Holt AC, Medzhitov R, Flavell R (2001) Recognition of double-stranded RNA and activation of NF-kB by toll-like receptor 3. Nature 413: 732-738

4. Alves, MP, Guzylack-Piriou, L, Juillard, V, Audonnet, JC, Doel, T, Dawson, H, Golde, WT, Gerber, H, Peduto, N, McCullough, KC, Summerfield, A (2009) Innate immune defenses induced by CpG do not promote vaccine-induced protection against foot-and-mouth disease virus in pigs. Clin Vaccine Immunol 16: 1151-1157

5. Anderson KV, Bokla L, Nüsslein-Volhard C (1985) Establishment of dorsalventral polarity in the Drosophila embryo: the induction of polarity by the Toll gene product. Cell 42: 791-798

6. Aramaki Y, Suda H and Tsuchiya S (1995) Interferon-gamma inductive effect of liposomes as an immunoadjuvant. Vaccine 13(18):1809-14

7. Arany I, Tyring SK, Brysk MM, Stanley MA, Tomai MA, Miller RL, Smith MH, McDermott DJ, Slade HB (2000) Correlation between pre-treatment levels of interferon response genes and clinical responses to an immune response modifier (Imiquimod) in genital warts. Antimicrob Agents and Chemother 44: $1869-1873$

8. Aucouturier J, Dupuis L, Ganne V (2001) Adjuvants designed for veterinary and human vaccines. Vaccine 19: 2666-2672

9. Baca-Estrada ME, Foldvari M, Snider M, van Drunen Littel-van den Hurk S and Babiuk LA (1997) Effect of IL4 and IL-12 liposomal formulations on the induction of immune response to bovine herpesvirus type-1 glycoprotein D. Vaccine $15(16): 1753-60$

10. Ballow M, Wang X, Xiang S, Allen C (2003) Expression and regulation of nuclear retinoic acid receptors in human lymphoid cells. J Clin Immunol $23: 46-54$

11. Barton GM, Medzhitov R (2003) Linking Toll-like receptors to IFN-a/b expression. Nature Immunology 4: 432-433

12. Bell JK, Mullen GE, Leifer CA, Mazzoni A, Davies DR, Segal DM (2003) Leucine-rich repeats and pathogen recognition in Toll-like receptors. Trends Immunol 24: 528-533

13. Belyakov IM, Ahlers JD, Berkofsky JA (2004) Mucosal AIDS vaccines: current status and future directions. Expert Rev Vaccines 3: S65-73

14. Beutner KR, Spruance SL, Hougham AJ, Fox TL, Owens ML, Douglas Jr JM (1998) Treatment of genital warts with an immune-response modifier (imiquimod). J Am Acad Dermatol 38: 230-239 
15. Bollinger JN (1970) Metabolic fate of mineral oil adjuvants using 14C-labeled tracers I: mineral oil. J Pharm Sci 59: 1084-1088

16. Booth, JS, Nichani, AK, Benjamin, P, Dar, A, Krieg, AM, Babiuk, LA, Mutwiri, GK (2007) Innate immune responses induced by classes of CpG oligodeoxynucleotides in ovine lymph and blood mononuclear cells. Vet Immunol Immunopathol 115: 24-34

17. Bowersock TL, HogenEsch H, Toregrosa S, Borie D, Wang B, Park H and Park K (1998) Induction of pulmonary immunity in cattle by oral administration of ovalbumin in alginate microspheres. Immunol Lett 60:3743

18. Brandhonneur N, Chevanne F, Vié V, Frisch B, Primault R, Le Potier MF, Le Corre P (2009) Specific and non-specific phagocytosis of ligandgrafted PLGA microspheres by macrophages. Eur J Pharm Sci 36:474-485

19. Brown WC, Estes DM, Chantler SE, Kegerreis KA, Suarez CE (1998) DNA and a CPG oligonucleotide derived from Babesia bovis are mitogenic for bovine B cells Infect Immun 66: 5423-5432

20. Campos M, Godson DL (2003) The effectiveness and limitations of immune memory: understanding protective immune responses. Int J Parasitol $33: 655-661$

21. Cargill EJ, Womack JE (2007) Detection of polymorphisms in bovine toll-like receptors 3, 7, 8 and 9. Genomics 89: 745-755

22. Charerntantanakul, W, (2009) Adjuvants for porcine reproductive and respiratory syndrome virus vaccines. Vet Immunol Immunopathol 129: 1-13

23. Choe J, Kelker MS, Wilson IA (2005) Crystal structure of human tolllike receptor 3 (TLR3) ectodomain. Science 309: 581-585

24. Creagh EM, O'Neill LA (2006) TLRs, NLRs and RLRs: a trinity of pathogen sensors that co-operate in innate immunity. Trends Immunol 27: $352-357$

25. Czerkinsky, C, Anjuere, F, McGhee, J R, George-Chandy, A, Holmgren, J, Kieny, M P, Fujiyashi, K, Mestecky, J F, Pierrefite-Carle, V, Rask, C, Sun, JB (1999) Mucosal immunity and tolerance: relevance to vaccine development. Immunol Rev 170: 197-222

26. Dalsgaard K, Hilgers L, Trouve G (1990) Classical and new approaches to adjuvant use in domestic food animals. Adv Vet Sci Comp Med 35: 121-128

27. Dar, A, Nichani, AK, Benjamin, P, Lai, K, Soita, H, Krieg, AM, Potter, A, Babiuk, LA, Mutwiri, GK (2008) Attenuated cytokine responses in porcine lymph node cells stimulated with CpG DNA are associated with low frequency of IFN-alpha-producing cells and TLR9 expression. Vet Immunol Immunopathol 123: 324-336

28. DeCicco KL, Zolfaghari R, Li N-Q, Ross AC (2000) Retinoic acid and polyriboinosinic acid act synergistically to enhance the antibody response to tetanus toxoid during vitamin A deficiency: possible involvement of interleukin-2 receptor-beta, signal transducer and activator of transcription-1, and interferon regulatory factor-1. J Infect Dis 182 Suppl 1: S29-36 
29. Dempsey PW, Vaidya SA, Cheng G (2003) The art of war: Innate and adaptive immune responses. Cell Mol Life Sci 60: 2604-2621

30. Dory, D, Béven, V, Torché, AM, Bougeard, S, Cariolet, R, Jestin, A (2005) CPG motif in ATCGAT hexamer improves DNA-vaccine efficiency against lethal Pseudorabies virus infection in pigs. Vaccine 23: 4532-4540

31. Dudda JC, Lembo A, Bachtanian E, Huehn J, Siewert C, HamannA, Kremmer E, Förster R, Martin SF (2005) Dendritic cells govern induction and reprogramming of polarized tissue-selective homing receptor patterns of T cells: important roles for soluble factors and tissue microenvironments. Eur J Immunol 35: 1056-1065

32. Dudda JC, Martin SF (2004) Tissue targeting of $T$ cells by DCs and microenvironments Trends Immunol 25: 417-421

33. Edelmann KH, Richardson-Burns S, Alexopoulou L, Tyler KL, Flavell RA, Oldstone MBA (2004) Does Toll-like receptor 3 play a biological role in virus infections? Virol 322: 231-238

34. Eisenbarth SC, Colegio OR, O'Connor W, Sutterwala FS, Flavell RA (2008) Crucial role for the Nalp3 inflammasome in the immunostimulatory properties of aluminium adjuvants. Nature 453: 1122-1126

35. Einer-Jensen K, Delgado L, Lorenzen E, Bovo G, Evensen $\varnothing$, Lapatra S, Lorenzen N (2009) Dual DNA vaccination of rainbow trout (Oncorhynchus mykiss) against two different rhabdoviruses, VHSV and IHNV, induces specific divalent protection. Vaccine 27:1248-1253

36. Enjoutina EY, Visic D, Daynes RA (2000) The induction of systemic and mucosal immune responses to antigen-adjuvant compositions administered into the skin: alterations in the migratory properties of dendritic cells appears to be important for stimulating mucosal immunity. Vaccine 18: $2753-2767$

37. Felder, C B, Vorlaender, N, Gander, B, Merkle, H P \& Bertschinger, H U (2000) Microencapsulated enterotoxigenic Escherichia coli and detached fimbriae for peroral vaccination of pigs. Vaccine 19: 706-715

38. Fenner F, Pastoret P-P, Blancou J, Terré J (1997) Historical Introduction. In: Pastoret, P-P, Blancou, J, Verschueren, C (eds) Veterinary Vaccinology. Elsevier Science, pp 3-19

39. Flohr F, Schneider-Schaulies S, Haller O, Kochs G (1999) The central interactive region of human MxA GTPase is involved in GTPase activation and interaction with viral target structures. FEBS Lett 463: 24-28

40. Foged C, Arigita C, Sundblad A, Jiskoot W, Storm G and Frokjaer S (2004) Interaction of dendritic cells with antigen-containing liposomes: effect of bilayer composition. Vaccine 22: 190313

41. Franchini M, Scheizer M, Matzener P, Maghouras I, Sauter K-S, Mirkovitch J, Peterhans E, Jungi TW (2006) Evidence for dissociation of TLR mRNA expression and TLR agonist-mediated functions in bovine macrophages. Vet Imm Immunopath 110: 37-49

42. Fraser CK, Diener KR, Brown MP, Hayball JD (2007) Improving vaccines by incorporating immunological coadjuvants. Expert Rev Vaccines 6: 559-578 
43. Fukanoki S, Matsumoto K, Mori H, Takeda R (2000) Effect of liquid paraffin on antibody responses and local adverse reactions of bivalent oil adjuvanted vaccines containing Newcastle Disease virus and Infectious Bronchitis virus. J Vet Med Sci 62: 1317-1319

44. Gangur V, Birmingham NP, Thanesvorakul S (2002) Chemokines in health and disease. Vet Immunol Immunopathol 86: 127-136

45. Gerdts V, Mutwiri GK, Tikoo SK, and Babiuk LA (2006) Mucosal delivery of vaccines in domestic animals. Vet Res 37: 487-510

46. Goldammer T, Zerbe H, Molenaar A, Schuberth HJ, Brunner RM, Kata SR, Seyfert HM (2004) Mastitis increases mammary mRNA abundance of b-defensin 5, toll-like receptor 2 (TLR2) and TLR4 but not TLR9 in cattle. Clin Diag Lab Imm 11: 174-185

47. Griebel, PJ, Broenlie, R, Manuja, A, Nichani, A, Mookherjee, N, Popowych, Y, Mutwiri, G, Hecker, R, Babiuk, LA (2005) Bovine toll-like receptor 9: A comparative analysis of molecular structure, function and expression. Vet Immunol Immunopathol 108: 11-16

48. Guy B (2007) The perfect mix: recent progress in adjuvant research. Nature Rev Microbiol 5: 505-517

49. Guzylack-Piriou L, Balmelli C, McCullough KC, Summerfield A Type-A CPG oligonucleotides activate exclusively porcine natural interferon-producing cells to secrete interferon-alpha, tumour necrosis factor-alpha and interleukin-12. Immunology 112: 28-37

50. Hargis AM, Ginn PE (2007) The integument. In: MacGavin MD, Zachary JF (eds) Pathological Basis of Veterinary Disease 4th ed. Mosby Elsevier, St Louis, pp 1167-1168

51. Harpin S, Hurley DJ, Mbikay M, Talbot B and Elazhary Y (1999) Vaccination of cattle with a DNA plasmid encoding the bovine viral diarrhoea virus major glycoprotein E2. J Gen Virol 80(Pt 12):3137-44

52. Hattori Y, Kawakami S, Suzuki S, Yamashita F and Hashida M (2004) Enhancement of immune responses by DNA vaccination through targeted gene delivery using mannosylated cationic liposome formulations following intravenous administration in mice. Biochem Biophys Res Commun $317,(4): 992-9$

53. Hendrick MJ, Brooks JJ (1994) Postvaccinal sarcomas in the cat: histology and immunohistochemistry. Vet Pathol 31: 126-129

54. Immordino ML, Dosio F and Cattel L (2006) Stealth liposomes: review of the basic science, rationale, and clinical applications, existing and potential. Int J Nanomedicine 1, (3):297-315

55. Iwasaki A (2007) Mucosal dendritic cells. Annu Rev Immunol 25: 381418

56. Iwata M, Hirakiyama A, Eshima Y, Kagechika H, Kato C, Song S (2004) Retinoic acid imprints gut-homing specificity on T cells. Immunity 21:527538 
57. Janeway CA, Jr (1989) Approaching the asymptote? Evolution and revolution in immunology. Cold Spring Harb Symp Quant Biol 54 Pt 1: 1-13

58. Janeway Jr CA, Medzhitov R (2002) Innate immune recognition. Annu Rev Immunol 20: 197-216

59. Jansen T, Hofmans MPM, Theelen MJG, Manders F, Schijns VEJC (2006) Structure- and oil type-based efficacy of emulsion adjuvants. Vaccine 24: $5400-5405$

60. Jego G, Palucka AK, Blanck JP, Chalouni C, Pascual V, Banchereau J (2003) Plasmacytoid dendritic cells induce plasma cell differentiation through type I interferon and interleukin- 6. Immunity 19: 225-234

61. Jelinek FE (2003) Postinflammatory sarcoma in cats. Exp Toxicol Pathol 55: 167-172

62. Jiang, H, Kang, M, Quan, J, Kang, S, Akaike, T, Yoo, H \& Cho, C S (2008) The potential of mannosylated chitosan microspheres to target macrophage mannose receptors in an adjuvant delivery system for intranasal immunization. Biomaterials 29: 1931-1939

63. Johansson-Lindbom B, Svensson M, Wurbel M-A, Malissen B, Márquez G, Agace W (2003) Selective generation of gut tropic $T$ cells in gutassociated lymphoid tissue (GALT) : requirement for GALT dendritic cells and adjuvant. J Ex Med 198: 963-969

64. Kakuda T, Sugimoto C, Onuma M (2001) Epitope-mapping of antigenspecific $\mathrm{T}$ lymphocyte in cattle immunized with recombinant major piroplasm surface protein of Theileria sergenti. J Vet Med Sci 63, (8):895-901

65. Kamstrup, S, Verthelyi, D, Klinman, DM (2001) Response of porcine peripheral blood mononuclear cells to CpG-containing oligodeoxynucleotides. Vet Microbiol 78: 353-362

66. Kamstrup, S, Frimann, TH, Barfoed, AM (2006) Protection of Balb/c mice against infection with FMDV by immunostimulation with CpG oligonucleotides. Antiviral Research 72: 42-48

67. Kang, M, Kang, S, Jiang, H, Guo, D, Lee, D, Rayamahji, N, Seo, Y, Cho, C\&Yoo, H (2008) Chitosan Microspheres Containing Bordetella bronchiseptica Antigens as Novel Vaccine Against Atrophic Rhinitis in Pigs. J Microbiol Biotechnol 18: 1179-85

68. Kapsenberg ML (2003) Dendritic-cell control of pathogen-driven T-cell polarization. Nature Rev Immunol 3: 984-993

69. Kass PH, Barnes WG Jr, Spangler WL, Chomel BB, Culbertson MR (1993) Epidemiologic evidence for a causal relation between vaccination and fibrosarcoma tumorigenesis in cats. J Am Vet Med Assoc 203: 396-405

70. Kass PH, Spangler WL, Hendrick MJ, McGill LD, Esplin DG, Lester S, Slater M, Meyer EK, Boucher F, Peters EM, Gobar GG, Htoo T, Decile K (2003) Multicenter case-control study of risk factors associated with development of vaccine-associated sarcomas in cats. J Am Vet Med Assoc 223: $1283-1292$

71. Kaufmann SHE (2007) The contribution of immunology to the rational design of novel antibacterial vaccines. Nature Rev Microbiol 5: 491-504 
72. Kavanagh OV, Earley B, Murray M, Foster CJ and Adair BM (2003) Antigen-specific IgA and IgG responses in calves inoculated intranasally with ovalbumin encapsulated in poly(DL-lactide-co-glycolide) microspheres. Vaccine 21:4472-4480

73. Kekarainen, T, Montoya, M, Dominguez, J, Mateu, E, Segalés, J (2008) Porcine circovirus type 2 (PCV2) viral components immunomodulate recall antigen responses. Vet Immunol Immunopathol 124: 41-49

74. Kieny MP, Girard MP (2005) Human vaccine research and development: An overview. Vaccine 23: 5705-5707

75. Kim B, Bowersock T, Griebel P, Kidane A, Babiuk LA, Sanchez M, AttahPoku S, Kaushik RS and Mutwiri GK (2002) Mucosal immune responses following oral immunization with rotavirus antigens encapsulated in alginate microspheres. J control Release 85:191-202

76. Kim, CH, Johnson, MC, Drennan, JD, Simon, BE, Thomann, E, Leong, JA (2000)DNA vaccines encoding viral glycoproteins induce nonspecific immunity and Mx protein synthesis in fish. J Virol 74: 7048-7054

77. Klinman, DM, Kamstrup, S, Verthelyi, D, Gursel, I, Ishii, KJ, Takeshita, F, Gursel, M (2000) Activation of the innate immune system by CpG oligodeoxynuclotides: immunoprotective activity and safety. Springer Sem Immunopathol 22: 173-183

78. Klinman, DM, Currie, D, Shirota, H (2007) Immunostimulatory CpG oligodeoxynucleotides as vaccine adjuvants. In: Singh, M (ed.) Vaccine Adjuvants and Delivery Systems. John Wiley and Sons, Inc, 157-174

79. Koppang EO, Haugarvoll E, Hordvik I, Aune L, Poppe T (2005) Vaccineassociated granulomatous inflammation and melanin accumulation in Atlantic salmon, Salmo salar L, white muscle. J Fish Dis 28: 13-22

80. Kovacs-Nolan J, Mapletoft JW, Latimer L, Babiuk LA, Hurk SD (2009) CpG oligonucleotide, host defense peptide and polyphosphazene act synergistically, inducing long-lasting, balanced immune responses in cattle. Vaccine 27: 2048-2054

81. Krieg AM, Yi AK, Matson S, Waldschmidt TJ, Bishop GA, Teasdale R, Koretzky GA, Klinman DM (1995) CpG motifs in bacterial DNA trigger direct B-cell activation. Nature 374: 546-549

82. Krieg, AM (2002) CPG motifs in bacterial DNA and their immune effects. Annu Rev Immunol 20: 709-760

83. Kringel, H, Dubey, JP, Beshah, E, Hecker, R, Urban, JF Jr. (2004) CpGoligodeoxynucleotides enhance porcine immunity to Toxoplasma gondii. Vet Parasitol 123: 55-66

84. Krug, A, Rothenfusser, S, Hornung, V, Jahrsdörfer, B, Blackwell, S, Ballas, ZK, Endres, S, Krieg, AM, Hartmann, G (2001) Identification of CpG oligonucleotide sequences with high induction of IFN- $\alpha / \beta$ in plasmacytoid dendritic cells. Eur J Immunol 31: 2154-2163 
85. Lampen A, Meyer S, Arnhold T, Nau H (2000) Metabolism of vitamin A and its active metabolite all-trans-retinoic acid in small intestinal enterocytes. J Pharmacol Exp Ther 295: 979-985

86. Lanzavecchia A, Sallusto F (2001) Regulation of T cell immunity by dendritic cells. Cell 106: 263-266

87. Laval A, Ganne V, Aucouturier J, Crespeau F, Levy D (1996) Efficacy and safety of new adjuvanted vaccine formulations containing inactivated exotoxin antigens from Pasteurella multocida. Proceedings of the 14 th IPVS Congress, Bologna 1996

88. Laval A, Ganne V, Aucouturier J, Deville S, Levy D (1998) Assessment of a new adjuvant range in a model for atrophic rhinitis. Proceedings of the 15th IPVS congress, Birmingham 1998

89. Le Bon A, Schiavoni G, D'Agostin G, Gresser I, Belardelli F, Tough DF (2001) Type I interferons potently enhance humoral immunity and can promote isotype switching by stimulating dendritic cells in vivo. Immunity $14: 461-470$

90. Lee SR, Pharr GT, Boyd BL, Pinchuk LM (2008) Bovine viral diarrhea viruses modulate toll-like receptors, cytokines and co-stimulatory molecules genes expression in bovine peripheral blood monocytes. Comp Immunol Microbiol Infect Dis 31: 403-418

91. Leserman L and Barois $N$ (1998) Major histocompatibility complex class II molecules, liposomes and antigen presentation. In: Lasic DD, Papahadjopoulos D (eds) Medical Applications of Liposomes. Elsevier, p 2545

92. Liebler-Tenorio EM and Pabst R (2006) MALT structure and function in farm animals. Vet Res 37: 257-280

93. Lin, J H, Weng, C N, Liao, C W, Yeh, K S \& Pan, M J (2003) Protective effects of oral microencapsulated Mycoplasma hyopneumoniae vaccine prepared by co-spray drying method. J Vet Med Sci 65: 69-74

94. Lindblad EB (2007) Safety evaluation of vaccine adjuvants. In: Singh M (ed) Vaccine Adjuvants and Delivery Systems. Wiley-Interscience 2007, pp $421-444$

95. Linghua Z, Xingshan T, Fengzhen Z (2008) In vivo oral administration effects of various oligodeoxynucleotides containing synthetic immunostimulatory motifs in the immune response to pseudorabies attenuated virus vaccine in newborn piglets. Vaccine 26: 224-233

96. Lund JM, Alexopoulou L, Sato A, Karow M, Adams NC, Gale MW, Iwasaki A, Flavell RA (2004) Recognition of single-stranded RNA viruses by Tolllike receptor 7. Proc Natl Acad Sci USA 101: 5598-5603

97. Mallick AI, Singha H, Chaudhuri P, Nadeem A, Khan SA, Dar KA and Owais M (2007) Liposomised recombinant ribosomal L7/L12 protein protects BALB/C mice against Brucella abortus 544 infection Vaccine 25(18):36923704

98. Marr AK, Kurzman ID and Vail DM (2004) Preclinical evaluation of a liposome-encapsulated formulation of cisplatin in clinically normal dogs. Am J Vet Res 65 (11):1474-8 
99. Maruyama K (2002) PEG-immunoliposome. Biosci Rep $22(2): 251-66$

100. Matsumoto M, Funami K, Oshiumi H, Seya T (2004) Toll-like receptor 3: A link between toll-like receptor, interferon and viruses. Microbiol Immunol 48: 147-154

101. Matsushima N, Tanaka T, Enchbayar P, Mikami T, Taga M, Yamada K, Kuroki Y (2007) Comparative sequence analysis of leucine-rich repeats (LRRs) within vertebrate toll-like receptors. BMC Genomics 8: 124-144

102. McKimmie CS, Johnson N, Fooks AR, Fazakerley JK (2005) Viruses selectively upregulate Toll-like receptors in the central nervous system. Biochem Biophys Res Comm 336: 925-933

103. Mena, A, Nichani, AK, Popowych, Y, Ioannou, XP, Godson, DL, Mutwiri, GK, Hecker, R, Babiuk, LA (2003) Bovine and ovine blood mononuclear leukocytes differ markedly in innate immune responses induced by class A and class B CpG-oligodeoxynucleotides. Oligonucleotides 13: 245-259

104. Menzies M, Ingham A (2005) Identification and expression of Toll-like receptors 1-10 in selected bovine and ovine tissue. Vet Immunol Immunopathol 109: 23-30

105. Mora JR, Bono MR, Manjunath N, Weninger W, Cavanagh LL, Rosemblatt M, von Andrian UH (2003) Selective imprinting of gut-homing $\mathrm{T}$ cells by Peyer's patch dendritic cells. Nature 424: 88-93

106. Mora JR, Iwata M, Eksteen B, Song SY, Junt T, Senman B, Otipoby KL, Yokota A, Takeuchi H, Ricciardi-Castagnoli P, Rajewsky K, Adams DH, von Andrian UH (2006) Generation of gut-homing IgA-secreting B cells by intestinal dendritic cells. Science 17: 1157-1160

107. Morton DB (2007) Vaccines and animal welfare. Rev sci tech Off int Epiz 26: 157-163

108. Mullin D (2003) Prometheus in Gloucestershire: Edward Jenner, 17491823. J Allergy Clin Immunol 112: 810-814

109. Munday JS, Stedman NL, Richey LJ (2003) Histology and immunohistochemistry of seven ferret vaccination-site fibrosarcomas. Vet Pathol 40: 288-293

110. Muneta Y, Uenishi H, Kikuma R, Yoshihara K, Shimoji Y, Yamamoto R, Hamashima N, Yokomizo Y, Mori Y (2003) Porcine TLR2 and TLR6: identification and their involvement in Mycoplasma hyopneumoniae infection. J Interferon Res 23: 583-590

111. Murphy PM (2001) Viral exploitation and subversion of the immune system through chemokine mimicry. Nature Immunol 2: 116-122

112. Mutwiri G, Bowersock T, Kidane A, Sanchez M, Gerdts V, Babieuk LA and Griebel P (2002) Induction of mucosal immune response following enteric immunization with antigen delivered in alginate microspheres. Vet Immunol Immunopathol 87:269-276

113. Mutwiri, GK, Nichani, AK, Babiuk, S, Babiuk, LA (2004) Strategies for enhancing the immunostimulatory effects of CpG oligodeoxynucleotides. J Controlled Release 97, 1-17 
114. Niborski V, Li Y, Brennan F, Lane M, Torche AM, Remond M, Bonneau M, Riffault S, Stirling C, Hutchings G, Takamatsu H, Barnett $P$, Charley B and Schwartz-Cornil I (2006) Efficacy of particle-based DNA delivery for vaccination of sheep against FMDV. Vaccine 24: 7204-7213

115. Nichani, AK, Dar, MA, Krieg, AM, Mirakhur, KK, Kaushik, RS, Griebel, PJ, Manuja, A, Townsend, HGG, Babiuk, LA, Mutwiri, GK (2007) Systemic innate immune responses following intrapulmonary delivery og CpG oligodeoxynucleotides in sheep. Vet Immunol Immunopathol 115: 357-368

116. Normile D (2008) Rinderpest Driven to extinction. Science 319: 16061609

117. O'Brien CN, Guidry AJ, Douglass LW and Westhoff DC (2001) Immunization with Staphylococcus aureus lysate incorporated into microspheres. J Dairy Sci 84: 1791-1799

118. Ortega-Villaizan, M, Chico, V, Falco, A, Perez, L, Coll, JM, Estepa, A (2009) The rainbow trout TLR9 gene and its role in the immune responses elicited by a plasmid encoding the glycoprotein G of the viral haemorrhagic septicaemia rhabdovirus (VHSV). Mol Immunol 46: 1710-1717

119. Ott G, van Nest G, (2007) Development of vaccine adjuvants: a historical perspective In Singh M (ed) Vaccine Adjuvants and Delivery Systems. Wiley-Interscience 2007, pp 1-31

120. Pasare C, Medzhitov R (2004) Toll-like receptors: linking innate and adaptive immunity. Microbes Infect 6: 1382-1387

121. Patel JR, Heldens, JGM (2009) Immunoprophylaxis against important virus diseases of horses, farm animals and birds. Vaccine 27: 1797-1810

122. Poirier VJ, Thamm DH, Kurzman ID, Jeglum KA, Chun R, Obradovich JE, O'Brien M, Fred RM 3rd, Phillips BS and Vail DM (2002) Liposomeencapsulated doxorubicin (Doxil) and doxorubicin in the treatment of vaccine-associated sarcoma in cats. J Vet Intern Med 16(6):726-31

123. Poppe TT, Barnes AC, Midtlyng P (2002) Welfare and ethics in fish farming. Bull Europ Ass Fish Pathol 22: 148-151

124. Proietti E, Bracci L, Puzelli S, Di Pucchio T, Sestill P, De Vincenzi E, Venditti M, Capone I, Seif I, De Maeyer E, Tough D, Donatelli I, Belardelii $F$ (2002) Type I IFN as a natural adjuvant for a productive immune response: Lessons from the influenza vaccine model. J Immunol 169: $375-383$

125. Pulendran B, Ahmed R (2006) Translating innate immunity into immunological memory: implications for vaccine development. Cell 124: 849863

126. Rebelatto MC, Guimond P, Bowersock TL and HogenEsch H (2001) Induction of systemic and mucosal immune response in cattle by intranasal administration of pig serum albumin in alginate microparticles. Vet Immunol Immunopathol $83(1-2): 93-105$

127. Richards JR, Elston TH, Ford RB, Gaskell RM, Hartmann K, Hurley KF, Lappin MR, Levy JK, Rodan I, Scherk M, Schultz RD, Sparkes AH (2006) The 
2006 American Association of Feline Practitioners Feline Vaccine Advisory Panel Report. J Am Vet Med Ass 229: 1405-1441

128. Rock KL, Hearn A, Chen CJ, Shi Y (2005) Natural endogenous adjuvants. Springer Semin Immunopathol 26: 231-246

129. Roth JA (1999) Mechanistic bases for adverse vaccine reactions and vaccine failures. Adv Vet Med 41: 681-700

130. Rughetti A, Biffoni M, Sabbatucci M, Rahimi H, Pellicciotta I, Fattorossi A, Pierelli L, Scambia G, Lavitrano M, Frati L and Nuti M (2000) Transfected human dendritic cells to induce antitumor immunity. Gene Ther $7(17): 1458-66$

131. Ruma guidelines Responsible use of vaccines and vaccinations in farm animal production Responsible use of medicines in agriculture alliance. Welwyn, 2006, pp 1-31

132. Saurer L, McCullough KC, Summerfield A (2007) In vitro induction of mucosa-type dendritic cells by all-trans retinoic acid. J Immunol 179: $3504-3514$

133. Scicchitano R, Husband AJ and Clancy RL (1984) Contribution of intraperitoneal immunization to the local immune response in the respiratory tract of sheep. Immunology 53 (2): 375-84

134. Singh M, O'Hagan DT (2003) Recent advances in veterinary vaccine adjuvants. Int J Parasitol 33: 469-478

135. Shi Y, Evans JE, Rock KL (2003) Molecular identification of a danger signal that alerts the immune system to dying cells. Nature 425: 516-521

136. Skountzou I, Quan F-S, Jacob J, Compans RW, Kang S-M (2006) Transcutaneous immunization with inactivated influenza virus induces protective immune responses. Vaccine 24: 6110-6119

137. Spickler AR, Roth JA (2003) Adjuvants in veterinary vaccines: modes of action and adverse effects. J Vet Intern Med 17: 273-281

138. Stagg AJ, Kamm MA, Knight SC (2002) Intestinal dendritic cells increase $\mathrm{T}$ cell expression of alpha4beta7 integrin. Eur J Immunol 32:14451454

139. Stanley AC, Huntley JF, Jeffrey M and Buxton D (2001) Characterization of ovine nasal-associated lymphoid tissue and identification of $\mathrm{M}$ cells in the overlying follicle-associated epithelium. J Comp Path 125:262-270

140. Steinman RM, Hemmi H (2006) Dendritic cells: translating innate to adaptive immunity. Curr Top Microbiol Immunol 311: 17-58

140a. Stills, HF (2005) Adjuvants and antibody production: dispelling the myths associated with Freund's complete and other adjuvants. ILAR Journal 46: 280-293.

141. Tabeta K, Georgl P, Janssen E, Du X, Hoebe K, Crozat K, Mudd S, Shamel L, Sovath S, Goode J, Alexopoulou L, Flavell RA, Beutler B (2004) Toll-like receptors 9 and 3 as essential components of innate immune 
defence against mouse cytomegalovirus. Proc Natl Acad Sci USA 101: 35163521

142. Tana, Watarai S, Lee JT, Onuma M, Ochiai K, Kakidani H and Yasuda T (1997) In vivo antitumor effect of cationic liposomes containing diphtheria toxin A-chain gene on cells infected with bovine leukemia virus. J Vet Med Sci 59(7):617-9

143. Thiele L, Rothen-Rutishauser B, Jilek S, Wunderli-Allenspach H, Merkle HP and Walter E (2001) Evaluation of particle uptake in human blood monocyte-derived cells in vitro. Does phagocytosis activity of dendritic cells measure up with macrophages? J Control Release 76(1-2):59-71

144. Tokunaga T, Yamamoto H, Shimada S, Abe H, Fukuda T, Fujisawa Y, Furutani Y, Yano O, Kataoka T, Sudo T, et al. (1984) Antitumor activity of deoxyribonucleic acid fraction from Mycobacterium bovis BCG. I. Isolation, physicochemical characterization, and antitumor activity. J Natl Cancer Inst 72 : 955-962

145. Torche, A M, Albina, E, Lecorre, P, Jestin, A \& Leverge, R (1999) Flow cytometric and optical microscopic evaluation of poly(D, L-lactide-coglycolide) microspheres phagocytosis by pig alveolar macrophages. J Controlled Release 58: 289-301

146. Torche, A M, Jouan, H, Le Corre, P, Albina, E, Primault, R, Jestin, A \& Le Verge, R (2000a) Ex vivo and in situ PLGA microspheres uptake by pig ileal Peyer's patch segment. Int J Pharm 201: 15-27

147. Torche, A M, Lecorre, P, Albina, E, Jestin, A \& Leverge, R (2000b) PLGA microspheres phagocytosis by pig alveolar macrophages: Influence of poly(Vinyl alcohol) concentration, nature of loaded-protein and copolymer nature. J Drug Target 7: 343-354

148. Torche, A M, Le Dimna, M, Le Corre, P, Mesplede, A, Le Gal, S, Cariolet, $\mathrm{R}$ \& Le Potier, M F (2006) Immune responses after local administration of IgY loaded-PLGA microspheres in gut-associated lymphoid tissue in pigs. Vet Immunol Immunopathol 109: 209-217

149. Tovey, M, C Lallemand, J-F Meritet, C Maury 2006 Adjuvant activity of interferon alpha: mechanism(s) of action. Vaccine 24: S2/46-47

150. U'Ren LW, Biller BJ, Elmslie RE, Thamm DH and Dow SW (2007) Evaluation of a novel tumor vaccine in dogs with hemangiosarcoma. J Vet Intern Med 21 (1):113-20

151. Van der Stede, Y, Verdonck, F, Vancaeneghem, S, Cox, E, Goddeeris, BM (2002) CpG-oligodinucleotides as an effective adjuvant in pigs for intramuscular immunizations. Vet Immunol Immunopathol 86: 31-41

152. Van Drunen Littel-van den Hurk S, Babiuk SL and Babiuk LA (2004) Strategies for improved formulation and delivery of DANN vaccines to veterinary targets species. Immunol Rev 199:113-125

153. Vascellari M, Melchiotti E, Bozza MA, Mutinelli F (2003) Fibrosarcomas at presumed sites of injection in dogs: characteristics and comparison with non-vaccination site fibrosarcomas and feline postvaccinal fibrosarcomas. J Vet Med A 50: 286-291 
154. Verfaillie T, Cox E, Goddeeris BM (2005) Immunostimulatory capacity of DNA vaccine vectors in porcine PBMC: a specific role for CpG-motifs? Vet Immunol Immunopathol 103: 141-151

155. Verthelyi, D, Ishii, KJ, Gursel, M, Takeshita, F, Klinman, DM (2001) Human peripheral blood cells differentially recognize and respond to two distinct CpG motifs. J Immunol 166: 2372-2377

156. Weng CN, Tzan YL, Liu SD, Lin SY, Lee CJ (1992) Protective effects of an oral microencapsulated Mycoplasma hyopneumoniae vaccine against experimental infection in pigs. Res Vet Sci 53:42-46

157. Werling D, Hope JC, Howard CJ, Jungi TW (2004) Differential production of cytokines, reactive oxygen and nitrogen by bovine macrophages and dendritic cells stimulated with Toll-like receptor agonists. Immunology 11: 41-52

158. Werling D, Coffey TJ (2007) Pattern recognition receptors in companion and farm animals - the key to unlocking the door to animal disease? Vet J 174: 240-251

159. Wille-Reece U, Flynn BJ, Lore K, Koup RA, Miles AP, Saul A, Kedl RM, Mattapallil JJ, Weiss WR, Roederer M, Seder RA (2006) Toll-like receptor agonists influence the magnitude and quality of memory $\mathrm{T}$ cell responses after prime-boost immunization in nonhuman primates. J Exp Med 203: 12491258

160. Wills-Karp M (2007) Complement activation pathways: a bridge between innate and adaptive immune responses in asthma. Proc Am Thorac Soc 4: 247251

161. Xiang SD, Scholzen A, Minigo G, David C, Apostolopoulos V, Mottram PL, Plebanski M (2006) Pathogen recognition and development of particulate vaccines: does size matter? Methods 40:1-9

162. Yu, H, Babiuk, LA, van Drunen Littel-van den Hurk, S (2004) Priming with CpG-enriched plasmid and boosting with protein formulated with CpG oligodeoxynucleotides and Quil A induces strong cellular and humoral immune responses to hepatitis C virus NS3. J Gen Virol 85: 1533-1543

163. Zaks K, Jordan M, Guth A, Sellins K, Kedl R, Izzo A, Bosio C, Dow S (2006) Efficient immunization and cross-priming by vaccine adjuvants containing TLR3 or TLR9 agonists complexed to cationic liposomes. J Immunol 176: 7335-7345

164. Zhou F and Neutra MR (2002) Antigen delivery to mucosa-associated lymphoid tissues using liposomes as a carrier. Biosciences Reports $22(2): 355-369$ 